\title{
APPLICATION AND VALIDATION OF THE NOTCH MASTER CURVE IN MEDIUM AND HIGH STRENGTH STRUCTURAL STEELS
}

\author{
S. Cicero ${ }^{1, *}$, T. García ${ }^{1}$, V. Madrazo ${ }^{2}$ \\ 1) Dpto. Ciencia e Ingeniería del Terreno y de los Materiales, LADICIM, Universidad de \\ Cantabria, Av/ Los Castros 44, 39005, Santander, Cantabria, Spain \\ 2) Fundación Centro Tecnológico de Componentes (CTC), Parque Científico y Tecnológico de \\ Cantabria (PCTCAN), C/ Isabel Torres $n^{\circ} 1,39011$, Santander, Spain \\ *corresponding author: ciceros@unican.es
}

\begin{abstract}
This paper applies and validates the Notch Master Curve in two ferritic steels with medium (steel S460M) and high (steel S690Q) strength. The Notch Master Curve is an engineering tool that allows the fracture resistance of notched ferritic steels operating within their corresponding ductile-to-brittle transition zone to be estimated. It combines the Master Curve and the Theory of Critical Distances in order to take into account the temperature and the notch effect respectively, assuming that both effects are independent.
\end{abstract}

The results, derived from 168 fracture tests on notched specimens, demonstrate the capability of the Notch Master Curve for the prediction of the fracture resistance of medium and high strength ferritic steels operating within their ductile-to-brittle transition zone and containing notches.

Keywords: Notch Master Curve, Notch effect, Master Curve, Theory of Critical Distances, Reference temperature.

\section{INTRODUCTION}

In practice, the load-bearing capacity of a structural component may be conditioned by the existence of stress risers: cracks, notches, welded joints, corners, etc. The different nature of these stress risers has generated different approaches when dealing with the corresponding

| structural integrity. This paper is focusese on notch-type defects, which may appear in structural components due to design details, mechanical damage, corrosion defects or fabrication defects. When notches are blunt, it is excessively conservative to proceed on the assumption that they behave like sharp cracks and to apply Fracture Mechanics criteria (i.e., such an assumption may lead to unnecessary repairs or replacements, or to oversizing). As shown in the literature (e.g, [1-9]), components with non-sharp defects or notches exhibit an apparent fracture toughness that is greater than that obtained in cracked components. This generally has direct consequences on the load-bearing capacity of the component and also on the corresponding structural integrity assessments (e.g, [7]).

Thus, the last two decades have seen a great deal of interest and research aimed at providing a notch theory capable of predicting the fracture behaviour of notched components. Although 
there have been different kinds of approaches, this work will consider only those included within the Theory of Critical Distances (TCD) $[1,10]$.

At the same time, it is known that the fracture resistance in cracked conditions of ferritic steels presents a clear dependence on the working temperature, with brittle behaviour at low temperatures (lower shelf, LS), ductile behaviour at high temperatures (upper shelf, US) and | transition behaviour between the two both of them (ductile-to-brittle transition zone, DBTZ). Fig. 1 represents a schematic of this type of behaviour. The DBTZ of ferritic steels in cracked conditions has been successfully modelled through the Master Curve (MC) [11-1519], understanding that, as stated in [15], ferritic steels are typically carbon, low-alloy, and higher alloy grades, whose typical microstructures are bainite, tempered bainite, tempered martensite, and ferrite and pearlite.

However, when dealing with ferritic steels in notched conditions, the analysis of the temperature effect on the fracture resistance cannot be analysed through-using the MC, given that it does not consider any notch effect. Consequently, the authors proposed the Notch Master Curve (NMC) [16], which assumes the independence between the temperature and the notch effects and combines the MC with the notch corrections provided by the TCD. The NMC was applied and validated in low and moderate strength ferritic-pearlitic steels (S275JR and S355J2, | respectively) by using $25 \mathrm{~mm}$ thick (1T) CT notched specimens [1620]. The aim of this paper is to provide further validation of the NMC under different conditions:

- Higher steel strengths: the validation will be performed on steels S460M and S690Q.

- Wider scope of microstructures: the corresponding microstructures are ferrite-pearlite (S460M), as in [1620], and bainite-tempered martensite (S690Q).

- Thinner specimens: all the tested specimens are $15 \mathrm{~mm}$ thick, which is equivalent to $0.6 \mathrm{~T}$ [15]. This allows the thickness effect to be analysed in conjunction with the temperature and the notch effect.

- SENB specimens: all the notched specimens have SENB geometry, whereas all the specimens tested in [1620] were CT specimens.

With all this, Section 2 gathers some theoretical background on the TCD, the MC and the NMC, Section 3 defines the experimental programme that is used here to validate the model, and Section 4 presents the corresponding validation by comparison between the experimental results and the NMC predictions. Lastly, Section 5 presents the conclusions.

\section{THEORETICAL BACKGROUND}

\subsection{The Theory of Critical Distances}

The Theory of Critical Distances (TCD) is actually a group of methodologies which consider a characteristic material length parameter (the critical distance, L) when performing fracture assessments $[1,10]$. The critical distance is given by Eq. (1): 
$L=\frac{1}{\pi}\left(\frac{K_{m a t}}{\sigma_{0}}\right)^{2}$

$\mathrm{K}_{\text {mat }}$ is the material fracture toughness and $\sigma_{0}$ is the inherent strength, which is generally larger than the ultimate tensile strength $\left(\sigma_{\mathrm{u}}\right)$ and must be calibrated.

Although the origins of the TCD date from the middle of the twentieth century [1721, 1822], it has been in this century that this theory has been comprehensively analysed and applied to different types of materials, processes (fracture and fatigue) and conditions (e.g., from linearelastic up to elastoplastic) (e.g., [2,3,1923 $-25 \underline{29}]$ ). A complete review of the TCD may be found in [1].

Among the different methodologies composing the TCD, two of them are particularly simple and interesting for the purposes of this research: the Point Method (PM) and the Line Method (LM) [8]:

- The PM establishes that fracture occurs when the stress reaches the inherent strength $\left(\sigma_{0}\right)$ at a distance from the defect tip equal to $L / 2$ :

$\sigma\left(\frac{L}{2}\right)=\sigma_{0}$

- The LM assumes that fracture occurs when the average stress along a distance equal to $2 \mathrm{~L}$ (starting from the notch tip), reaches the inherent strength, $\sigma_{0}$ :

$\frac{1}{2 L} \int_{0}^{2 L} \sigma(r) d r=\sigma_{0}$

The predictions provided by the two methodologies are slightly different [1], but both of them provide similar results to the experimental ones (e.g., [1-3]). Additionally, the PM and the LM provide expressions [1] for the apparent fracture toughness $\left(\mathrm{K}^{\mathrm{N}}\right.$ mat $)$ exhibited by notched components. These expressions are based on the stress distribution on the notch tip provided by Creager and Paris [26이:

$$
\sigma(r)=\frac{K_{I}}{\sqrt{\pi}} \frac{2(r+\rho)}{(2 r+\rho)^{3 / 2}}
$$

In case of By using the PM fracture criteria (Eq. (2)), together with the definition of the critical distance L (Eq. (1)) and the Paris-Creager stress distribution (Eq. (4)), and establishing that failure takes place when $\mathrm{K}_{\mathrm{I}}$ is equal to $\mathrm{K}^{\mathrm{N}}$ mat, Eq. (5) may be easily obtained:

$$
K_{m a t}^{N}=K_{m a t} \frac{\left(1+\frac{\rho}{L}\right)^{3 / 2}}{\left(1+\frac{2 \rho}{L}\right)}
$$


Likewise, the application of the LM provides Eq. (6):

$$
K_{m a t}^{N}=K_{m a t} \sqrt{1+\frac{\rho}{4 L}}
$$

As shown in [7], these expressions (which provide similar results) may be used in the structural integrity assessment of notched components.

\subsection{The Master Curve}

The Master Curve (MC) [11-1519] constitutes a fracture characterisation tool for ferritic steels within their ductile-to-brittle transition zone (DBTZ). It is based on statistical considerations, related to the distribution of cleavage-promoting particles around the crack tip. At the end, fracture is controlled by weakest link statistics and follows a three parameter Weibull distribution. Hence, within the scope of small-scale yielding conditions, the cumulative failure probability $\left(\mathrm{P}_{\mathrm{f}}\right)$ on which the MC is based follows Eq. (7):

$$
P_{f}=1-e^{-\frac{B}{B_{0}}\left(\frac{K_{J c}-K_{\min }}{K_{0}-K_{\min }}\right)^{b}}
$$

$\mathrm{K}_{\mathrm{Jc}}$ is the fracture toughness for the selected failure probability $\left(\mathrm{P}_{\mathrm{f}}\right), \mathrm{K}_{0}$ is a scale parameter located at the $63.2 \%$ cumulative failure probability level, $\mathrm{B}$ is the specimen thickness and $\mathrm{B}_{0}$ is the reference specimen thickness assumed in this methodology $\left(\mathrm{B}_{0}=25 \mathrm{~mm}\right.$, also referred to as $1 \mathrm{~T}) . \mathrm{K}_{\min }$ and $\mathrm{b}$ take the same values for all ferritic steels and have been experimentally fitted, providing $20 \mathrm{MPam}^{1 / 2}$ and 4 , respectively. Therefore, it can be observed that the fracture characterisation within the DBTZ is performed by using $\mathrm{K}_{\mathrm{Jc}}$, which is an elastic-plastic equivalent stress intensity factor derived from the J-integral at the point of onset of cleavage fracture, $\mathrm{J}_{\mathrm{c}}$.

The dependence of $\mathrm{K}_{0}$ on temperature under cleavage fracture conditions follows Eq. (8) [11$13,27 \underline{31}$ :

$$
K_{0}=31+77 e^{0.019 \cdot\left[T-T_{0}\right]}
$$

$\mathrm{T}_{0}$ is the reference temperature, corresponding to the temperature where the median fracture toughness for a $25 \mathrm{~mm}$ thick specimen is $100 \mathrm{MPam}^{1 / 2}$. Consequently, the only parameter required to define the temperature dependence of $\mathrm{K}_{\mathrm{Jc}}$ is the material reference temperature. Furthermore, whichever the ferritic steel is, and once the corresponding $\mathrm{T}_{0}$ is known, it is possible to define the MC for any probability of failure $\left(\mathrm{P}_{\mathrm{f}}\right)$ :

$$
K_{J c, P_{f}}=20+\left(-\ln \left(1-P_{f}\right)\right)^{0.25}\left(11+77 e^{0.019\left(T-T_{0}\right)}\right)
$$

Thus, in $25 \mathrm{~mm}$ thick specimens, the curves associated to probabilities of failure of $95 \%, 50 \%$ and $5 \%$ are, respectively, those gathered in Eqs. (10)-(12): 


$$
\begin{aligned}
& K_{J c 0.95}=34.5+101.3 \cdot e^{0.019\left(T-T_{0}\right)} \\
& K_{J c 0.50}=30+70 \cdot e^{0.019\left(T-T_{0}\right)} \\
& K_{J c 0.05}=25.2+36.6 \cdot e^{0.019\left(T-T_{0}\right)}
\end{aligned}
$$

The experimental and analytical procedure that allows $\mathrm{T}_{0}$ to be determined is gathered in [15].

When the specimen or component thickness is not $25 \mathrm{~mm}$, [15] provides Eq. (13) relating the fracture toughness value for a $25 \mathrm{~mm}$ thick specimen $\left(\mathrm{B}_{0}\right)$ with the fracture toughness value corresponding to any other thickness $\left(\mathrm{B}_{\mathrm{x}}\right)$ :

$$
K_{J c(x)}=20+\left[K_{J c(0)}-20\right]\left(\frac{B_{0}}{B_{x}}\right)^{1 / 4}
$$

This equation, used to model size effects in the $\mathrm{DBTZ}_{2}$ is based on the statistical weakest-link theory [15]. Thus, when predicting the fracture toughness in a specimen whose thickness is $B_{x}$, and for a given probability of failure $\left(\mathrm{P}_{\mathrm{f}}\right)$, Eqs. (9) and (13) can be combined, providing Eq. (14):

$$
K_{J c(x)}=20+\left[\left(-\ln \left(1-P_{f}\right)\right)^{0.25}\left(11+77 e^{0.019\left(T-T_{0}\right)}\right)\right]\left(\frac{B_{0}}{B_{x}}\right)^{1 / 4}
$$

Analogously, Eqs. (10)-(12) must be substituted by Eqs. (15)-(17):

$$
\begin{aligned}
& K_{J c(x) 0.95}=20+\left[14.5+101.3 \cdot e^{0.019\left(T-T_{0}\right)}\right]\left(\frac{B_{0}}{B_{x}}\right)^{1 / 4} \\
& K_{J c(x) 0.50}=20+\left[10+70 \cdot e^{0.019\left(T-T_{0}\right)}\right]\left(\frac{B_{0}}{B_{x}}\right)^{1 / 4} \\
& K_{J c(x) 0.05}=20+\left[5.2+36.6 \cdot e^{0.019\left(T-T_{0}\right)}\right]\left(\frac{B_{0}}{B_{x}}\right)^{1 / 4}
\end{aligned}
$$

\subsection{The Notch-Master Curve}

As explained in [1620], the NMC arises from the combination of the MC and the TCD, and it is based on the following assumptions: 
- The reference temperature, $\mathrm{T}_{0}$, on which the $\mathrm{MC}$ is based, is a material constant regardless of the type of defect being analysed. Consequently, this parameter has full validity in notched conditions.

- The different notch corrections provided by the TCD generate similar estimations of $\mathrm{K}^{\mathrm{N}}$ mat, as shown in [1-4]. Here, for the sake of simplicity, the notch correction provided by the LM will be used (Eq. (6)), but the expressions shown below would be totally analogous in case of when using any other methodology included within the TCD.

- Although the TCD has a linear-elastic nature, it generates good predictions of apparent fracture toughness and load-bearing capacity under (limited) elastic-plastic conditions, such as those existing within the DBTZ, provided the calibration of the TCD parameters is conveniently performed (e.g., [1620, 2327]]).

An additional assumption, concerning the size (thickness) effect is included here: this effect is included in the MC through Eq. (13), and it is independent of the notch effect.

With all this, the expressions of the NMC are straightforward. For a given thickness $\left(B_{x}\right)$ these would be Eqs. (18)-(20):

$$
\begin{aligned}
& K_{J c(x) 0.95}^{N}=\left[20+\left[14.5+101.3 \cdot e^{0.019\left(T-T_{0}\right)}\right]\left(\frac{B_{0}}{B_{x}}\right)^{1 / 4}\right] \cdot \sqrt{1+\frac{\rho}{4 L}} \\
& K_{J c(x) 0.50}^{N}=\left[20+\left[10+70 \cdot e^{0.019\left(T-T_{0}\right)}\right]\left(\frac{B_{0}}{B_{x}}\right)^{1 / 4}\right] \cdot \sqrt{1+\frac{\rho}{4 L}} \\
& K_{J c(x) 0.05}^{N}=\left[20+\left[5.2+36.6 \cdot e^{0.019\left(T-T_{0}\right)}\right]\left(\frac{B_{0}}{B_{x}}\right)^{1 / 4}\right] \cdot \sqrt{1+\frac{\rho}{4 L}}
\end{aligned}
$$

Here, it should be noted that the subscripts $0.95,0.50$ and 0.05 indicate that the corresponding apparent fracture toughness predictions come from the MC estimations associated to probabilities of failure of, respectively, $95 \%, 50 \%$ and $5 \%$, but they do not necessarily imply the same exact probabilities of failure for the NMC predictions, given that the notch effect is simply fitted through least squares methodology (see below).

Finally, the application of the NMC requires determining $\mathrm{T}_{0}$, which is obtained by testing cracked specimens following [15], and the value of L along the DBTZ.

\section{EXPERIMENTAL PROGRAM}

The experimental program is composed of 168 SENB notched specimens, $15 \mathrm{~mm}$ thick, made of two different materials: steel S460M [2832] and steel S690Q [2933]. The specimens, LT oriented, were obtained from $15 \mathrm{~mm}$ thick plates. The notch radii analysed here are $0 \mathrm{~mm}$ (crack-type defect), $0.15 \mathrm{~mm}, 0.25 \mathrm{~mm}, 0.5 \mathrm{~mm}, 1.0 \mathrm{~mm}$ and $2.0 \mathrm{~mm}$. For the two materials, the 
specimens were tested at $-100^{\circ} \mathrm{C},-120^{\circ} \mathrm{C}$ and $-140^{\circ} \mathrm{C}$, all of them belonging to the corresponding DBTZ (see below).

Fig. 2 shows the geometry of the specimens, Fig. 3 shows the microstructure of the two steels, Table 1 gathers the chemical compositions, and Table 2 shows some of the main mechanical properties. The tensile tests (two per material) were performed following [3034], whereas Charpy tests were performed following [3135].

Tables 3 and 4 gather the whole experimental program, showing the material, the testing temperature, the notch radius and the apparent fracture toughness $\left(\mathrm{K}^{\mathrm{N}}\right.$ mat $)$ result of every single tested SENB specimen. As seen in the tables, 5 of the tests were not valid and do not present any $\mathrm{K}^{\mathrm{N}}$ mat result. The $\mathrm{K}^{\mathrm{N}}$ mat values have been obtained following the procedure specified in [15] for the determination of $\mathrm{K}_{\mathrm{Jc}}$ in cracked specimens. Therefore:

$K_{m a t}^{N}=\sqrt{J_{m a t}^{N} \frac{E}{1-v^{2}}}$

$\mathrm{J}^{\mathrm{N}}{ }_{\text {mat }}$ is the apparent $\mathrm{J}$-integral at onset of cleavage fracture, $\mathrm{E}$ is the Young's modulus and $v$ is the Poisson's ratio [15]:

$J_{m a t}^{N}=J_{e}^{N}+J_{p}^{N}=\frac{\left(1-v^{2}\right)\left(K_{e}^{N}\right)^{2}}{E}+\frac{\eta A_{p}}{B b_{0}}$

$\mathbf{J}^{\mathrm{N}}{ }_{\mathrm{e}}$ and $\mathbf{J}^{\mathrm{N}}$ are, respectively, the elastic and plastic components of $\mathbf{J}^{\mathrm{N}}{ }_{\text {mat }}, \eta$ is a dimensionless constant, $A_{p}$ is the plastic area under the load-displacement curve, $b_{0}$ is the initial remaining ligament, $\mathrm{B}$ the specimen thickness $\left(\mathrm{B}_{\mathrm{x}}=15 \mathrm{~mm}\right)$ and $\mathrm{K}_{\mathrm{e}}^{\mathrm{N}}$ is the apparent elastic stress intensity factor at instability [15]:

$K_{e}^{N}=\left(\frac{P \cdot S}{B \cdot W^{3 / 2}}\right) \frac{3 \cdot\left(\frac{a}{W}\right)^{1 / 2}\left[1.99-\left(\frac{a}{W}\right)\left(1-\frac{a}{W}\right)\left(2.15-3.93\left(\frac{a}{W}\right)+2.7\left(\frac{a}{W}\right)^{2}\right)\right]}{2 \cdot\left(1+2 \frac{a}{W}\right)\left(1-\frac{a}{W}\right)^{3 / 2}}$.

$\mathrm{P}$ is the applied load at onset of cleavage fracture, $\mathrm{W}$ the specimen width, $\mathrm{S}$ the specimen span and a the defect length. As shown in tables 3 and 4, and following [15], the results obtained in $15 \mathrm{~mm}$ thick $(0.6 \mathrm{~T})$ cracked specimens were also converted into their corresponding $25 \mathrm{~mm}$ thick (1.0T) equivalents (Eq. (13)), in order to generate the data used for the estimation of $\mathrm{T}_{0}$.

Finally, as an example, Fig. 4 shows some load-displacement curves obtained in the tests, where it can be observed how the greater the notch radius the larger the displacement at rupture.

\section{RESULTS AND DISCUSSION}

This section presents the validation of the NMC predictions (Eqs. (18)-(20)), by their comparison to the experimental results gathered in Section 3 (Eq. (21)). 
Firstly, it is necessary to determine the reference temperature $\left(\mathrm{T}_{0}\right)$ of the steels being analysed. The fracture toughness results obtained in cracked specimens allow this parameter to be determined. Applying [15] and following the multi-temperature option, reference temperatures of $-91.8^{\circ} \mathrm{C}$ and $-110.8^{\circ} \mathrm{C}$ were obtained for steels S460M and S690Q, respectively. These results confirm that the above mentioned testing temperatures $\left(-100^{\circ} \mathrm{C},-120^{\circ} \mathrm{C}\right.$ and $\left.-140^{\circ} \mathrm{C}\right)$ belong to the validity range of the DBTZ defined in [15], which is $\mathrm{T}_{0} \pm 50^{\circ} \mathrm{C}$.

Secondly, in order to apply Eqs. (18)- (20), it is necessary to determine the critical distance. This may be performed by a combination of experimental work covering different notch radii (at least two different radii) and finite elements modelling, or by fitting experimental results also covering different notch radii (in such a case, more than two radii would be required) (e.g., [14]). In On this occasion $\mathrm{L}$ will be calibrated by using the second approach: Figs. 5-6 show the $\mathrm{L}$ values, one per temperature, providing the best fit (least squares) of the LM (Eq. (6)) to the experimental data. The values obtained are shown in Table 5 .

Fig. 7 shows the values of $\mathrm{L}$ for both steels, and the corresponding second order fitting equations. These are Eqs. (24)-(25) for steels S460M and S690Q, respectively:

$L=0.00000858 \cdot T^{2}-0.0019968 \cdot T-0.1086$

$L=-0.00000298 \cdot T^{2}-0.0004634 \cdot T+0.000525$

As explained in [1620], Eqs. (24) (in the case of steel S460M) and (25) (steel S690Q) may be introduced in Eqs. (18)-(20) to provide apparent fracture toughness estimations. However, although in both materials there are differences between the three values of $\mathrm{L}$ obtained at the different temperatures, they all have the same order of magnitude and the effect of using one or another is mitigated by the fact that $\mathrm{L}$ is squared in the different expressions considering the notch effect. Therefore, for the sake of simplicity, a constant value of $L$ (the average value) may be considered (0.0052 $\mathrm{mm}$ for steel S460M and $0.0115 \mathrm{~mm}$ for steel S690Q).

With all this, Fig. 8 shows the predictions of the NMC for steel S460M, and their comparison with the experimental results when using the average value of $\mathrm{L}(0.0052 \mathrm{~mm})$. These are the main observations:

- It can be observed that the MC (and the NMC) provides reasonable predictions for cracked specimens, although two of the experimental points are located outside the area defined between $\mathrm{K}_{\mathrm{Jc} 0.95}$ and $\mathrm{K}_{\mathrm{Jc} 0.05}$.

- In the case of specimens containing $0.15 \mathrm{~mm}$ notch radii, when using the average value of $\mathrm{L}$, there are three experimental results located below the $\mathrm{K}_{\mathrm{Jc} 0.05}$ predictions. For these points, the NMC provides unsafe predictions. This is caused by the fitting process of the $\mathrm{K}^{\mathrm{N}}$ mat results provided by the TCD in Fig. 5, where the predictions for $0.15 \mathrm{~mm}$ notch radii are generally higher than the experimental results (see Figs. 5a and 5c). This, again, has direct consequences on the NMC predictions.

- The predictions obtained for a notch radius of $0.25 \mathrm{~mm}$ present the highest deviations when compared to the experimental results: the four points at $-140{ }^{\circ} \mathrm{C}$ are located below the $\mathrm{K}_{\text {Jc } 0.05}^{\mathrm{N}}$ curve (unsafe situation). Again, Fig. $5 \mathrm{c}$ provides a clue for these results: the experimental points obtained for a $0.25 \mathrm{~mm}$ notch radius are located well below the 
fitting curve used to estimate the notch effect. Thus, there is an overestimation of the notch effect with consequences on the NMC predictions.

- The predictions for a notch radius of $0.50 \mathrm{~mm}$ are better than those obtained for 0.25 $\mathrm{mm}$, with two results below the $\mathrm{K}_{\mathrm{Jc} 0.05}^{\mathrm{N}}$ curve.

- All the results (25 experimental points) obtained for notch radii of $1.0 \mathrm{~mm}$ and $2.0 \mathrm{~mm}$ are located between the $\mathrm{K}_{\mathrm{Jc} 0.95}$ and the $\mathrm{K}_{\mathrm{Jc} 0.05}$ predictions. Thus, the predictions have been better in those cases with significant plasticity (e.g., $2.0 \mathrm{~mm}$ notch radius at higher temperatures), when the scope of both the TCD and the MC may be theoretically exceeded.

With all this, for steel S460M, when using the average value of $\mathrm{L}$, the NMC provides good predictions of the apparent fracture toughness at $-100^{\circ} \mathrm{C}$ and $-120^{\circ} \mathrm{C}$, and several unsafe predictions at $-140^{\circ} \mathrm{C}$. In any case, most of the predictions are located between the curves associated to probabilities of failure of $5 \%$ and $95 \%$. More precisely, there are 12 results (out of 81 ) outside the area defined by the $\mathrm{K}_{\mathrm{Jc} 0.95}$ and the $\mathrm{K}_{\mathrm{Jc} 0.05}$ lines, which is a very similar relation to that provided by the MC in the cracked specimens ( 2 out of 14 are located outside such area).

The results at $-140^{\circ} \mathrm{C}$ are good for the larger radii $(1.0 \mathrm{~mm}$ and $2.0 \mathrm{~mm})$, whereas for $0.15 \mathrm{~mm}$, $0.25 \mathrm{~mm}$ and 0.50 notch radii the predictions were often unsafe, something that has been justified by the overestimation of the notch effect performed during the calibration process of $\mathrm{L}$.

Concerning steel S690Q (see Fig.9), the main observations are the following:

- The MC provides good predictions in cracked specimens, although there is one experimental result located above the $95 \%$ line (at $-100{ }^{\circ} \mathrm{C}$ ). This, in any case, corresponds to a conservative situation.

- The results are reasonable for the whole range between $0.15 \mathrm{~mm}$ and $2.0 \mathrm{~mm}$ notch radii, although there are experimental results located outside the area defined by the $5 \%$ and the $95 \%$ lines.

- The results obtained for a $0.15 \mathrm{~mm}$ notch radius are good, with just one point located below the $5 \%$ line (at $-100{ }^{\circ} \mathrm{C}$ ). It This corresponds to an experimental point located well below the fitting curve used in the calibration of L (see Fig. 6a).

- All the results for a notch radius of $0.25 \mathrm{~mm}$ are located between the $\mathrm{K}_{\mathrm{Jc}} 0.95$ and the $\mathrm{K}_{\mathrm{Jc} 0.05}$ lines.

- The results obtained for a $0.50 \mathrm{~mm}$ notch radius present the highest deviations. At $140^{\circ} \mathrm{C}$, there are two points below the $5 \%$ line and two points above the $95 \%$ line, so the NMC has not been able in this case to capture the high scatter observed here. This It may indicate that the notch effect provides additional scatter to that provided by the temperature effect. In any case, Fig. 6c explains the reasons for $\theta$ these results.

- The results obtained for notch radii of $1.0 \mathrm{~mm}$ and $2.0 \mathrm{~mm}$ are good, with just two experimental points with significant deviations when compared to the NMC predictions.

Therefore, the predictions of the NMC in steel S690Q have also been reasonable, with 71 experimental results (out of 84 ) located between the $\mathrm{K}_{\mathrm{Jc} 0.95}$ and the $\mathrm{K}_{\mathrm{Jc} 0.05}$ lines.

In order to avoid the above detected-unsafe predictions detected above, one possibility would be to estimate L by using lower envelopes for the experimental results gathered in Figs. 5-6. This would provide higher values of $\mathrm{L}$ than those obtained through the least squares methodology 
and lower predictions of the notch effect, with direct reductions in the NMC predictions of the material fracture resistance. Of course, this possibility would also provide overconservative estimations in many situations. As an example, the $\mathrm{L}$ value providing the lower envelope of the experimental results in steel $\mathrm{S} 460 \mathrm{M}\left(\mathrm{L}_{\mathrm{LE}}\right)$ is $0.02 \mathrm{~mm}$ for the three temperatures being analysed (see Fig. 10). The corresponding predictions of the NMC are presented in Fig. 11, where it can be seen that all the experimental results are located above the $\mathrm{K}_{\mathrm{Jc} 0.05}$ lines, but many of the predictions are highly overconservative (e.g., see Fig. 11c). Similar results, with an $\mathrm{L}_{\mathrm{LE}}$ value of $0.09 \mathrm{~mm}$, would be obtained in steel S690Q.

\section{CONCLUSIONS}

This paper applies and validates the Notch Master Curve (NMC) for the analysis of the apparent fracture toughness within the ductile-to-brittle transition zone of structural steels S460M and S690Q. The NMC combines the Theory of Critical Distances and the Master Curve, which are well known methodologies for the analysis of the notch effect and the temperature effect (respectively) on the material fracture resistance. Thus, the NMC allows the evolution of the apparent fracture toughness within the ductile-to-brittle transition zone of ferritic-pearltic steels to be predicted.

An experimental program composed of 168 SENB specimens has been completed, covering notch radii from $0 \mathrm{~mm}$ up to $2.0 \mathrm{~mm}$, and the two above mentioned steels, which have been tested at three different temperatures within their corresponding transition zone.

The application of the Notch Master Curve to the experimental results has provided reasonable results. Several unsafe predictions have been observed, all of them being justified by the least squares fitting process that has been used for the calibration of the critical distance. The use of lower envelopes has been suggested in order to avoid this kind of unsafe results, although this methodology generates numerous overconservative predictions.

The obtained results obtained, together with those previously published by the authors on steels S275JR and S355J2, provide a wide scope of materials where the NMC has been applied with satisfactory results.

\section{Acknowledgements}

The authors of this work would like to express their gratitude to the Spanish Ministry of Science and Innovation for the financial support of the project MAT2010-15721: 'Análisis de integridad estructural en defectos tipo entalla', on the results of which this paper is based.

\section{References}

[1] D. Taylor, The theory of critical distances: a new perspective in fracture mechanics. Elsevier, UK, (2007).

[2] S. Cicero, V. Madrazo, I.A. Carrascal IA, Analysis of notch effect in PMMA by using the Theory of Critical Distances, Eng. Fract. Mech. 86 (2012) 56-72.

[3] V. Madrazo, S. Cicero, I.A. Carrascal, On the point method and the line method notch effect predictions in Al7075-T651, Eng. Fract. Mech. 79 (2012) 363-379. 
[4] S. Cicero, V. Madrazo, T. García, J. Cuervo, E. Ruiz, On the notch effect in load bearing capacity, apparent fracture toughness and fracture mechanisms of polymer PMMA, aluminium alloy A17075-T651 and structural steels S275JR and S355J2, Eng. Fail. Anal. 29 (2013) 108121.

[5] S. Cicero, V. Madrazo, T. García, Analysis of notch effect in the apparent fracture toughness and the fracture micromechanisms of ferritic-pearlitic steels operating within their lower shelf, Eng. Fail. Anal. 36 (2014) 322-342.

[6] S. Cicero, V. Madrazo, I.A. Carrascal, R. Cicero, Analysis of notch effect in fracture micromechanisms, Proc. of ASME PVP2012, paper $n^{\circ}$ PVP2012-78008, Toronto, Ontario, Canada. (2012).

[7] S. Cicero, V. Madrazo, I.A. Carrascal, R. Cicero, Assessment of notched structural components using failure assessment diagrams and the theory of critical distances, Eng. Fract. Mech. 78 (2011) 2809-2825.

[8] L.S. Niu, C. Chehimi, G. Pluvinage, Stress field near a large blunted V notch and application of the concept of notch stress intensity factor to the fracture of very brittle materials, Eng. Fract. Mech. 49 (1994) 325-335.

[9] G. Pluvinage, Fatigue and fracture emanating from notch; the use of the notch stress intensity factor, Nucl. Eng. Des. 185 (1998) 173-184.

[10] D. Taylor, P. Cornetti, N. Pugno, The fracture mechanics of finite crack extension, Eng. Fract. Mech. 72 (2005) 1021-1038.

[11] K. Wallin, The scatter in KIc results, Eng. Fract. Mech. 19 (1984) 1085-1093.

[12] K. Wallin, T. Saario, K. Törrönen, Statistical model for carbide induced brittle fracture in steel, Metal. Sci. 18 (1984) 13-16.

[13] K. Wallin, The size effect in KIc results, Eng. Fract. Mech. 22 (1985) 149-163.

[14] T.L. Anderson, Fracture mechanics: fundamentals and applications, 3rd ed, CRC Press, Florida, USA, (2004).

[15] ASTM 1921-13a, Test method for the determination of reference temperature $T_{0}$ for ferritic steels in the transition range, American Society for Testing and Materials, Philadelphia, USA (2013).

[16] K. Wallin, S. Pallaspuro, I. Valkonen, P. Karjalainen-Roikonen, P. Suikkanen, Fracture properties of high performance steels and their welds, Eng. Fract. Mech. 135 (2015) 219-231.

[17] M. Scibetta, Master Curve analysis of potentially inhomogeneous materials, Eng. Fract. Mech. 94 (2012) 56-70.

[18] S.B. Choi, S. Choi, J.B. Choi, Y.S. Chang, M.C. Kim, B.S. Lee, Enhancement of master curve method for inhomogeneos material, J. Mech. Sci. Technol. 26 (2012) 2727-2734.

[19] S.B. Choi, Y.S. Chang, Y.J. Kim, M.C. Kim, B.S. Lee, Correction of constraint loss in fracture toughness measurement of PCVN specimens based on fracture toughness diagram, $J$. Mech. Sci. Technol. 24 (2010) 687-692.

[1620] S. Cicero, V. Madrazo, T. García, The Notch Master Curve: a proposal of Master Curve for ferritic-pearlitic steels in notched conditions, Eng. Fail. Anal. 42 (2014) 178-196.

| [1721] H. Neuber, Theory of notch stresses: principles for exact calculation of strength with reference to structural form and material, Springer Verlag, Berlin, (1958).

| [1822] R.E. Peterson, Notch sensitivity, In: G. Sines, J.L. Waisman (Eds.), Metal fatigue, McGraw Hill, New York, USA, (1959) 293-306.

| [1923] D. Taylor, G. Wang, The validation of some methods of notch fatigue analysis, Fatig. Fract. Eng. Mater. Struct. 23 (2000) 387-394.

[2024] D. Taylor, A mechanistic approach to critical-distance methods in notch fatigue, Fatig. Fract. Eng. Mater. Struct. 24 (2001) 215-224. 
[21 25] L. Susmel, D. Taylor, Fatigue design in the presence of stress concentrations, J. Strain Anal. Eng. Des. 38 (2003) 443-452.

[2226] D. Taylor, P. Bologna, K. Bel Knani, Prediction of fatigue failure location on a component using a critical distance method, Int. J. Fatig. 22 (2000) 735-742.

| [2327] L. Susmel, D. Taylor, On the use of the Theory of Critical Distances to predict failures in ductile metallic materials containing different geometrical features, Eng. Fract. Mech. 75 (2008) $4410-4421$.

[2428] L. Susmel, D. Taylor, An elasto-plastic reformulation of the Theory of Critical Distances to estimate lifetime of notched components failing in the low/medium-cycle fatigue regime, $J$. Eng. Mater. Technol. Trans. ASME, 132 (2010) 0210021-28.

| [2529] S. Cicero, V. Madrazo, I.A. Carrascal, On the Point Method load-bearing capacity predictions in Al7075-T651 structural components containing stress risers, Eng. Fail. Anal. 26 (2012) 129-138.

| [2630] M. Creager, C. Paris, Elastic field equations for blunt cracks with reference to stress corrosion cracking, Int. J. Fract. 3 (1967) 247-252.

[2731] K. Wallin, Master curve analysis of ductile to brittle transition region fracture toughness round robin data. The "EURO' fracture toughness curve, VTT Publications 367, JulkaisijaUtgivare Publisher, Finland, (1998).

| [2832] EN 10025-4:2004, Technical delivery conditions for thermomechanical rolled weldable fine grain structural steels, European Committee for Standardization, (2004).

| [2933] EN 10025-6:2004, Technical delivery conditions for flat products of high yield strength structural steels in the quenched and tempered condition, European Committee for Standardization, (2004).

[3034] ASTM E8/E8M-13a, Standard test methods for tension testing of metallic materials, American Society for Testing and Materials, Philadelphia, USA (2013).

[3135] ASTM E23-12c, Standard test methods for notched bar impact testing of metallic materials American Society for Testing and Materials, Philadelphia, USA (2012). 


\section{Table and Figure Captions}

Table 1. Chemical composition of the two materials being analysed

Table 2. Mechanical properties of the two materials being analysed: $\sigma_{\mathrm{y}}$, yield stress; $\sigma_{\mathrm{u}}$, ultimate tensile strength; $\mathrm{e}_{\max }$, strain under maximum load; T27J, temperature providing a Charpy energy of 27J. RT: Room Temperature.

Table 3. Description of specimens and experimental results. Steel S460M.

Table 4. Description of specimens and experimental results. Steel 690Q.

Table 5. $\mathrm{L}$ values for steels S460M and S690Q.

Figure 1. Schematic showing the different regions of fracture behaviour in ferritic steels.

Figure 2. Schematic of SENB fracture specimens. Dimensions in mm. Notch radii $(\rho)$ vary from $0 \mathrm{~mm}$ (crack-type defects) up to $2.0 \mathrm{~mm}$.

Figure 3. Microstructure of the two steels being tested: a) steel S460M, with ferritic-pearlic microstructure; b) steel S690Q, showing bainite and tempered martensite.

Figure 4. Load-displacement curves of steel $460 \mathrm{M}$ at $-100^{\circ} \mathrm{C}$ : a) specimen $4-7$ (notch radius $=$ $0.15 \mathrm{~mm}), \mathrm{b})$ specimen 4-20 (notch radius $=0.5 \mathrm{~mm})$; specimen 4-32 (notch radius $=2.0 \mathrm{~mm}$ ).

Figure 5. Apparent fracture toughness in steel S460M: experimental results and LM best fit predictions: a) $-100^{\circ} \mathrm{C}$; b) $-120^{\circ} \mathrm{C}$; c) $-140^{\circ} \mathrm{C}$.

Figure 6. Apparent fracture toughness in steel S690Q: experimental results and LM best fit predictions: a) $-100^{\circ} \mathrm{C}$; b) $-120^{\circ} \mathrm{C}$; c) $-140^{\circ} \mathrm{C}$.

Figure 7. L values at different temperatures, second order fitting equation and average value: a) steel S460M; b) steel S690Q.

Figure 8. Comparison between experimental results and NMC predictions in steel S460M. $\mathrm{L}=0.0052 \mathrm{~mm}$ (average value): a) notch radius $=0 \mathrm{~mm}$ (crack-like defect); $\mathrm{b}$ ) notch radius = $0.15 \mathrm{~mm} ; \mathrm{c}$ ) notch radius $=0.25 \mathrm{~mm} ; \mathrm{d}$ ) notch radius $=0.5 \mathrm{~mm} ; \mathrm{e})$ notch radius $=1.0 \mathrm{~mm} ; \mathrm{f}$ ) notch radius $=2.0 \mathrm{~mm}$.

Figure 9. Comparison between experimental results and NMC predictions in steel S690Q. L= $0.0115 \mathrm{~mm}$ (average value): a) notch radius $=0 \mathrm{~mm}$ (crack-like defect); $\mathrm{b}$ ) notch radius $=0.15$ $\mathrm{mm}$; $\mathrm{c}$ ) notch radius $=0.25 \mathrm{~mm} ; \mathrm{d}$ ) notch radius $=0.5 \mathrm{~mm}$; e) notch radius $=1.0 \mathrm{~mm} ; \mathrm{f}$ ) notch radius $=2.0 \mathrm{~mm}$.

Figure 10. Apparent fracture toughness in steel S460M: experimental results and LM lower envelope: a) $-100^{\circ} \mathrm{C}$; b) $-120^{\circ} \mathrm{C}$; c) $-140^{\circ} \mathrm{C}$ 
Figure 11. Comparison between experimental results and NMC predictions in steel S460M.

$\mathrm{L}_{\mathrm{LE}}=0.02 \mathrm{~mm}$ (lower envelope): a) notch radius $=0.25 \mathrm{~mm}$; ) notch radius $=0.50 \mathrm{~mm} ; \mathrm{c}$ ) notch radius $=2.0 \mathrm{~mm}$. 


\section{Tables and Figures}

Table 1. Chemical composition of the two materials being analysed

\begin{tabular}{|l|c|c|c|c|c|c|c|c|c|c|c|c|c|}
\hline Steel & $\mathbf{C}$ & $\mathbf{S i}$ & $\mathbf{M n}$ & $\mathbf{P}$ & $\mathbf{S}$ & $\mathbf{C r}$ & $\mathbf{M o}$ & $\mathbf{N i}$ & $\mathbf{A l}$ & $\mathbf{C u}$ & $\mathbf{N b}$ & $\mathbf{T i}$ & $\mathbf{V}$ \\
\hline S460M & 0.12 & 0.45 & 1.49 & 0.012 & 0.001 & 0.062 & 0.001 & 0.016 & 0.048 & 0.011 & 0.036 & 0.003 & 0.066 \\
\hline S690Q & 0.15 & 0.40 & 1.42 & 0.006 & 0.001 & 0.020 & 0.002 & 0.160 & 0.056 & 0.010 & 0.029 & 0.003 & 0.058 \\
\hline
\end{tabular}


Table 2. Mechanical properties of the two materials being analysed: $\sigma_{y}$, yield stress; $\sigma_{u}$, ultimate tensile strength; $\mathrm{e}_{\max }$, strain under maximum load; T27J, temperature providing a Charpy energy of 27J. RT: Room Temperature.

\begin{tabular}{|c|c|c|c|c|}
\hline Material & $\boldsymbol{\sigma}_{\mathbf{y}}(\mathbf{M P a}), \mathbf{R T}$ & $\boldsymbol{\sigma}_{\mathbf{u}}(\mathbf{M P a}), \mathbf{R T}$ & $\mathbf{e}_{\max }(\boldsymbol{\%})$ & $\mathbf{T}_{\text {27J }}\left({ }^{\mathbf{0}} \mathbf{C}\right)$ \\
\hline S460M & 473 & 595 & 30 & -103 \\
\hline S690Q & 775 & 832 & 20 & -94 \\
\hline
\end{tabular}


Table 3. Description of specimens and experimental results. Steel S460M.

\begin{tabular}{|c|c|c|c|c|}
\hline Specimen & Temperature $\left({ }^{\circ} \mathrm{C}\right)$ & $\rho(\mathbf{m m})$ & $\mathbf{K}^{\mathbf{N}}{ }_{\text {mat }}$ & $\mathbf{K}^{\mathrm{N}}{ }_{\text {mat } 1 \mathrm{~T}}$ \\
\hline $4-1$ & \multirow{36}{*}{-100} & \multirow{6}{*}{0} & 101.34 & 91.58 \\
\hline $4-2$ & & & 70.41 & 64.37 \\
\hline $4-3$ & & & 107.99 & 97.44 \\
\hline $4-4$ & & & 66.40 & 60.84 \\
\hline $4-5$ & & & 88.90 & 80.64 \\
\hline $4-6$ & & & 96.47 & 87.30 \\
\hline $4-7$ & & \multirow{6}{*}{0.15} & 280.12 & \\
\hline $4-8$ & & & 171.58 & \\
\hline 4-9 & & & 249.17 & \\
\hline 4-10 & & & 150.03 & \\
\hline $4-11$ & & & 192.94 & \\
\hline $4-12$ & & & 217.94 & \\
\hline $4-13$ & & \multirow{6}{*}{0.25} & 335.49 & \\
\hline $4-14$ & & & 362.83 & \\
\hline $4-15$ & & & 322.90 & \\
\hline $4-16$ & & & 307.59 & \\
\hline $4-17$ & & & 175.23 & \\
\hline $4-18$ & & & 264.64 & \\
\hline $4-19$ & & \multirow{6}{*}{0.50} & 377.74 & \\
\hline $4-20$ & & & 463.50 & \\
\hline $4-21$ & & & 479.66 & \\
\hline $4-22$ & & & 487.88 & \\
\hline $4-23$ & & & 462.45 & \\
\hline $4-24$ & & & 486.43 & \\
\hline $4-25$ & & \multirow{6}{*}{1.0} & 643.76 & \\
\hline $4-26$ & & & 581.03 & \\
\hline $4-27$ & & & 581.38 & \\
\hline $4-28$ & & & 610.71 & \\
\hline 4-29 & & & - & \\
\hline 4-30 & & & 595.77 & \\
\hline $4-31$ & & \multirow{6}{*}{2.0} & - & \\
\hline $4-32$ & & & 878.40 & \\
\hline $4-33$ & & & - & \\
\hline $4-34$ & & & 910.84 & \\
\hline $4-35$ & & & 852.46 & \\
\hline $4-36$ & & & 932.95 & \\
\hline 4-37 & \multirow{7}{*}{-120} & \multirow{4}{*}{0} & 125.97 & 113.26 \\
\hline $4-38$ & & & 94.41 & 85.49 \\
\hline $4-39$ & & & 82.97 & 75.42 \\
\hline $4-40$ & & & 49.83 & 46.26 \\
\hline $4-41$ & & \multirow{3}{*}{0.15} & 174.78 & \\
\hline $4-42$ & & & 256.59 & \\
\hline $4-43$ & & & 156.28 & \\
\hline
\end{tabular}




\begin{tabular}{|c|c|c|c|c|}
\hline 4-44 & & & 274.74 & \\
\hline $4-45$ & & \multirow{4}{*}{0.25} & 281.00 & \\
\hline $4-46$ & & & 337.87 & \\
\hline $4-47$ & & & 201.69 & \\
\hline $4-48$ & & & 249.56 & \\
\hline 4-49 & & \multirow{4}{*}{0.50} & 320.25 & \\
\hline 4-50 & & & 286.45 & \\
\hline 4-51 & & & 345.77 & \\
\hline 4-52 & & & 327.78 & \\
\hline $4-53$ & & \multirow{4}{*}{1.0} & 568.84 & \\
\hline 4-54 & & & 483.46 & \\
\hline 4-55 & & & 410.69 & \\
\hline $4-56$ & & & 405.45 & \\
\hline 4-57 & & \multirow{4}{*}{2.0} & 781.88 & \\
\hline 4-58 & & & 863.28 & \\
\hline 4-59 & & & 799.14 & \\
\hline 4-60 & & & \begin{tabular}{|l}
723.92 \\
\end{tabular} & \\
\hline $4-61$ & \multirow{24}{*}{-140} & \multirow{4}{*}{0} & 44.55 & 41.606 \\
\hline $4-62$ & & & 36.08 & 34.153 \\
\hline $4-63$ & & & 46.63 & 43.435 \\
\hline 4-64 & & & 55.15 & 50.939 \\
\hline $4-65$ & & & 149.70 & \\
\hline $4-66$ & & 0 & 153.25 & \\
\hline 4-67 & & 0.15 & 140.98 & \\
\hline 4-68 & & & 111.92 & \\
\hline 4-69 & & & 103.69 & \\
\hline 4-70 & & 025 & 138.74 & \\
\hline 4-71 & & 0.25 & 128.74 & \\
\hline 4-72 & & & 135.38 & \\
\hline 4-73 & & & 145.26 & \\
\hline 4-74 & & 050 & 135.77 & \\
\hline 4-75 & & 0.50 & 218.73 & \\
\hline $4-76$ & & & 303.21 & \\
\hline 4-77 & & & 366.71 & \\
\hline 4-78 & & 10 & 451.60 & \\
\hline 4-79 & & 1.0 & 363.43 & \\
\hline 4-80 & & & 481.48 & \\
\hline 4-81 & & & 729.42 & \\
\hline 4-82 & & 0 & 670.69 & \\
\hline 4-83 & & 2.0 & 787.83 & \\
\hline 4-84 & & & \begin{tabular}{|l|}
712.64 \\
\end{tabular} & \\
\hline
\end{tabular}


Table 4. Description of specimens and experimental results. Steel 690Q.

\begin{tabular}{|c|c|c|c|c|}
\hline Specimen & Temperature $\left({ }^{\circ} \mathrm{C}\right)$ & $\rho(\mathbf{m m})$ & $\mathbf{K}^{\mathbf{N}}{ }_{\text {mat }}$ & $\mathbf{K}^{\mathrm{N}}{ }_{\text {mat } 1 \mathrm{~T}}$ \\
\hline $6-1$ & \multirow{36}{*}{-100} & \multirow{6}{*}{0} & 117.69 & 105.98 \\
\hline $6-2$ & & & 197.97 & 176.63 \\
\hline $6-3$ & & & 92.37 & 83.69 \\
\hline $6-4$ & & & 127.92 & 114.99 \\
\hline $6-5$ & & & 91.49 & 82.92 \\
\hline $6-6$ & & & - & - \\
\hline $6-7$ & & \multirow{6}{*}{0.15} & 123.22 & \\
\hline $6-8$ & & & 300.14 & \\
\hline $6-9$ & & & 297.60 & \\
\hline $6-10$ & & & 308.89 & \\
\hline $6-11$ & & & 252.07 & \\
\hline $6-12$ & & & 277.66 & \\
\hline $6-13$ & & \multirow{6}{*}{0.25} & 301.14 & \\
\hline $6-14$ & & & 315.03 & \\
\hline $6-15$ & & & 276.03 & \\
\hline $6-16$ & & & 312.33 & \\
\hline $6-17$ & & & 237.90 & \\
\hline $6-18$ & & & - & \\
\hline $6-19$ & & \multirow{6}{*}{0.50} & 372.59 & \\
\hline $6-20$ & & & 212.76 & \\
\hline $6-21$ & & & 404.72 & \\
\hline $6-22$ & & & 389.78 & \\
\hline $6-23$ & & & 418.26 & \\
\hline $6-24$ & & & 393.01 & \\
\hline $6-25$ & & \multirow{6}{*}{1.0} & 520.67 & \\
\hline $6-26$ & & & 281.95 & \\
\hline $6-27$ & & & 500.51 & \\
\hline $6-28$ & & & 524.05 & \\
\hline 6-29 & & & 498.65 & \\
\hline $6-30$ & & & 518.51 & \\
\hline $6-31$ & & \multirow{6}{*}{2.0} & 646.52 & \\
\hline $6-32$ & & & 610.96 & \\
\hline $6-33$ & & & 675.89 & \\
\hline $6-34$ & & & 703.18 & \\
\hline $6-35$ & & & 719.56 & \\
\hline $6-36$ & & & 749.93 & \\
\hline 6-37 & \multirow{7}{*}{-120} & \multirow{4}{*}{0} & 65.67 & 60.19 \\
\hline $6-38$ & & & 118.14 & 106.37 \\
\hline $6-39$ & & & 120.23 & 108.21 \\
\hline $6-40$ & & & 111.16 & 100.23 \\
\hline $6-41$ & & \multirow{3}{*}{0.15} & 133.93 & \\
\hline $6-42$ & & & 233.80 & \\
\hline $6-43$ & & & 134.77 & \\
\hline
\end{tabular}




\begin{tabular}{|c|c|c|c|c|}
\hline $6-44$ & & & 203.22 & \\
\hline $6-45$ & & \multirow{4}{*}{0.25} & 265.41 & \\
\hline 6-46 & & & 309.61 & \\
\hline $6-47$ & & & 239.97 & \\
\hline $6-48$ & & & 246.56 & \\
\hline $6-49$ & & \multirow{4}{*}{0.50} & 367.32 & \\
\hline 6-50 & & & 370.67 & \\
\hline $6-51$ & & & 376.98 & \\
\hline $6-52$ & & & 405.76 & \\
\hline $6-53$ & & \multirow{4}{*}{1.0} & 492.36 & \\
\hline 6-54 & & & 320.61 & \\
\hline 6-55 & & & 436.61 & \\
\hline 6-56 & & & 478.71 & \\
\hline 6-57 & & \multirow{4}{*}{2.0} & 816.37 & \\
\hline 6-58 & & & 411.96 & \\
\hline 6-59 & & & 719.33 & \\
\hline 6-60 & & & 659.54 & \\
\hline 6-61 & \multirow{24}{*}{-140} & \multirow{4}{*}{0} & 54.82 & 50.642 \\
\hline $6-62$ & & & 72.80 & 66.474 \\
\hline $6-63$ & & & 70.67 & 64.595 \\
\hline 6-64 & & & 78.18 & 71.201 \\
\hline 6-65 & & & 115.31 & \\
\hline 6-66 & & 015 & 100.50 & \\
\hline 6-67 & & 0.15 & 145.16 & \\
\hline 6-68 & & & 102.00 & \\
\hline 6-69 & & & 128.70 & \\
\hline 6-70 & & 025 & 150.37 & \\
\hline $6-71$ & & $0.2 J$ & 182.53 & \\
\hline $6-72$ & & & 133.52 & \\
\hline 6-73 & & & 356.65 & \\
\hline $6-74$ & & 05 & 110.39 & \\
\hline $6-75$ & & 0.3 & 119.30 & \\
\hline 6-76 & & & 364.10 & \\
\hline $6-77$ & & & 469.83 & \\
\hline 6-78 & & 10 & 489.31 & \\
\hline 6-79 & & 1.0 & 248.83 & \\
\hline $6-80$ & & & 481.71 & \\
\hline $6-81$ & & & 656.82 & \\
\hline 6-82 & & 20 & 648.72 & \\
\hline $6-83$ & & 2.0 & 636.15 & \\
\hline 6-84 & & & 719.13 & \\
\hline
\end{tabular}


Table 5. L values for steels S460M and S690Q.

\begin{tabular}{|c|c|c|}
\hline Steel & Temperature $\left({ }^{\mathbf{}} \mathbf{C}\right)$ & $\mathbf{L}(\mathbf{m m})$ \\
\hline \multirow{3}{*}{ S460M } & -100 & 0.0053 \\
\cline { 2 - 3 } & -120 & 0.0075 \\
\cline { 2 - 3 } & -140 & 0.0028 \\
\hline \multirow{3}{*}{ S690Q } & -100 & 0.0170 \\
\cline { 2 - 3 } & -120 & 0.0131 \\
\cline { 2 - 3 } & -140 & 0.0069 \\
\hline
\end{tabular}




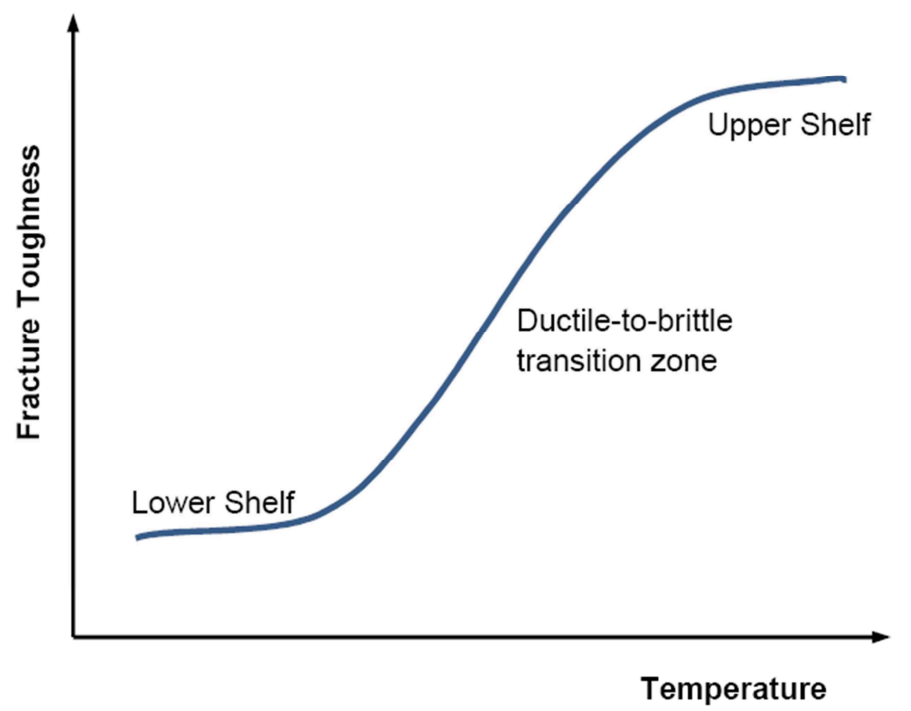

Figure 1. Schematic showing the different regions of fracture behaviour in ferritic steels. 

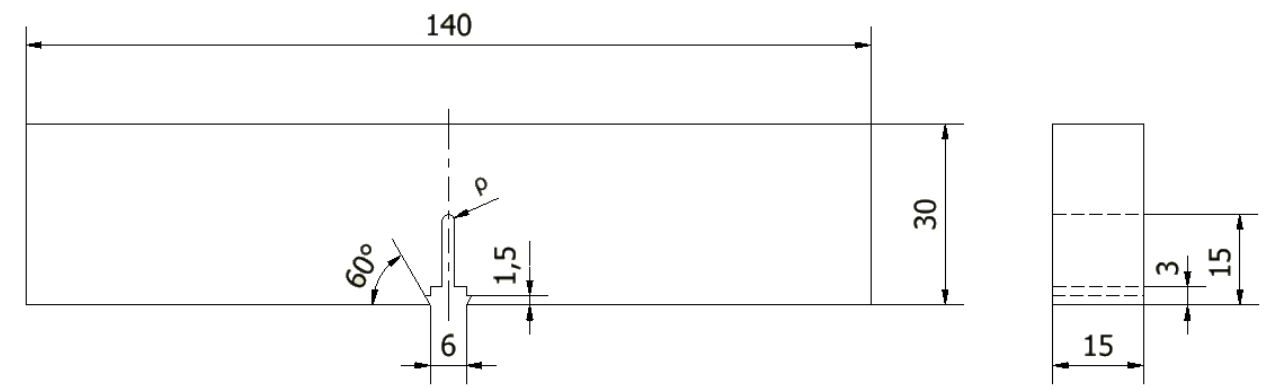

Figure 2. Schematic of SENB fracture specimens. Dimensions in mm. Notch radii $(\rho)$ vary from $0 \mathrm{~mm}$ (crack-type defects) up to $2.0 \mathrm{~mm}$. 


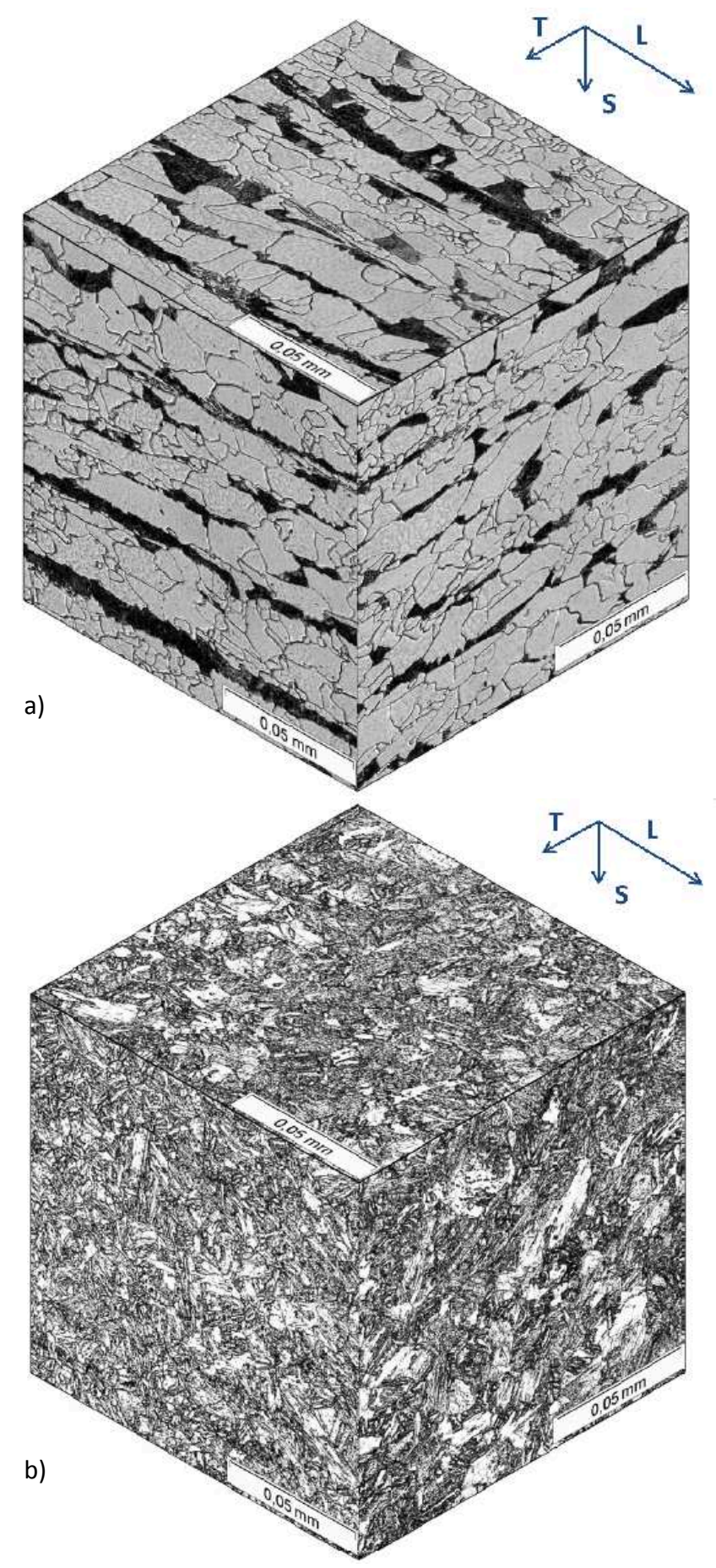

Figure 3. Microstructure of the two steels being tested: a) steel S460M, with ferritic-pearlic microstructure; b) steel S690Q, showing bainite and tempered martensite. 


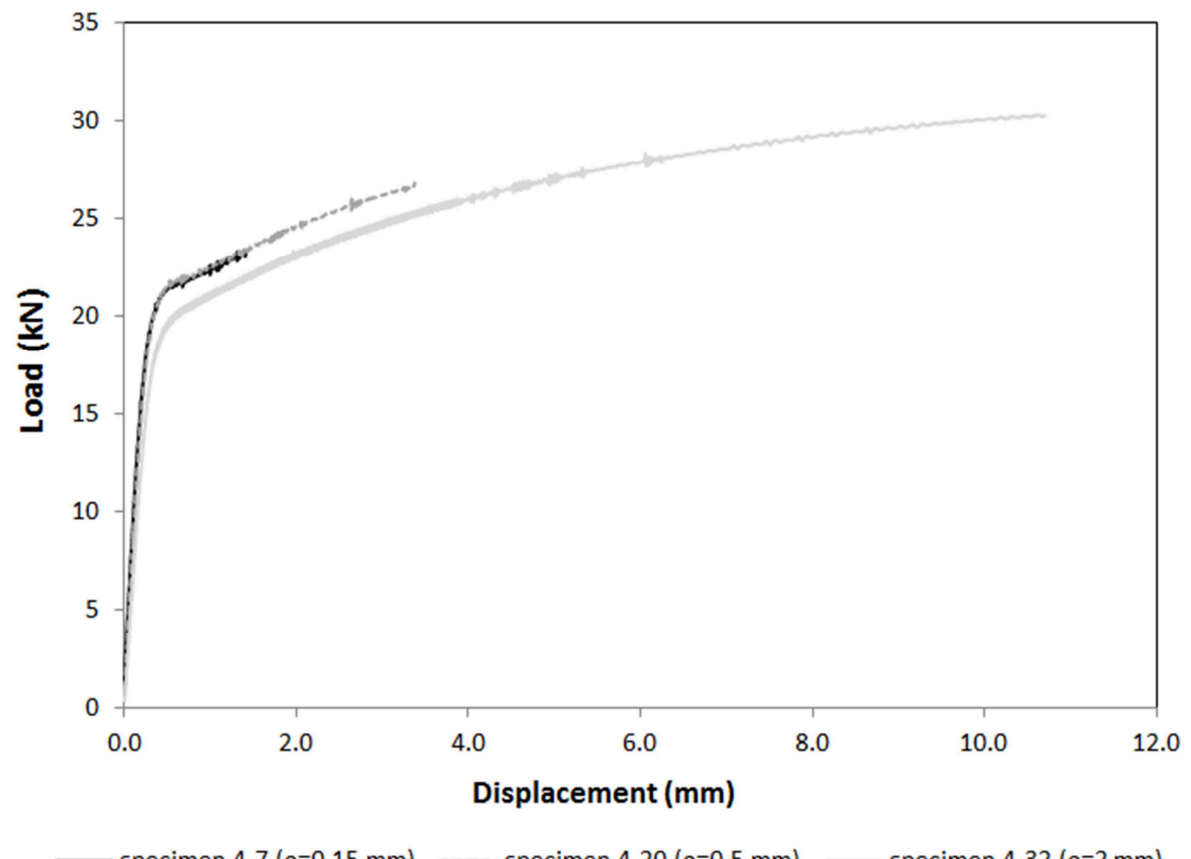

Figure 4. Load-displacement curves of steel $460 \mathrm{M}$ at $-100^{\circ} \mathrm{C}$ : a) specimen $4-7$ (notch radius $=$ $0.15 \mathrm{~mm}), \mathrm{b})$ specimen 4-20 (notch radius $=0.5 \mathrm{~mm})$; specimen $4-32($ notch radius $=2.0 \mathrm{~mm})$. 


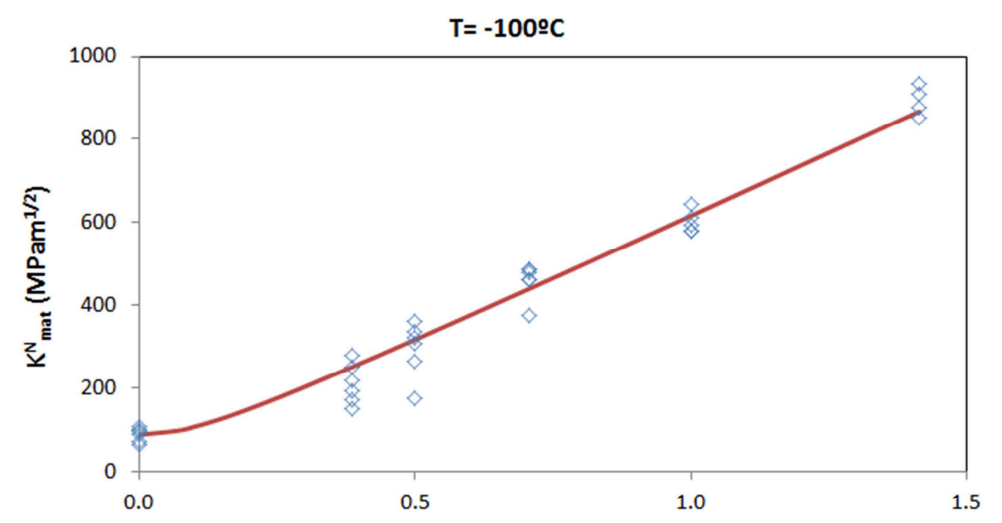

a)

$\rho^{1 / 2}$

— LM predictions $(\mathrm{L}=0.0053 \mathrm{~mm}) \quad \diamond$ experimental results

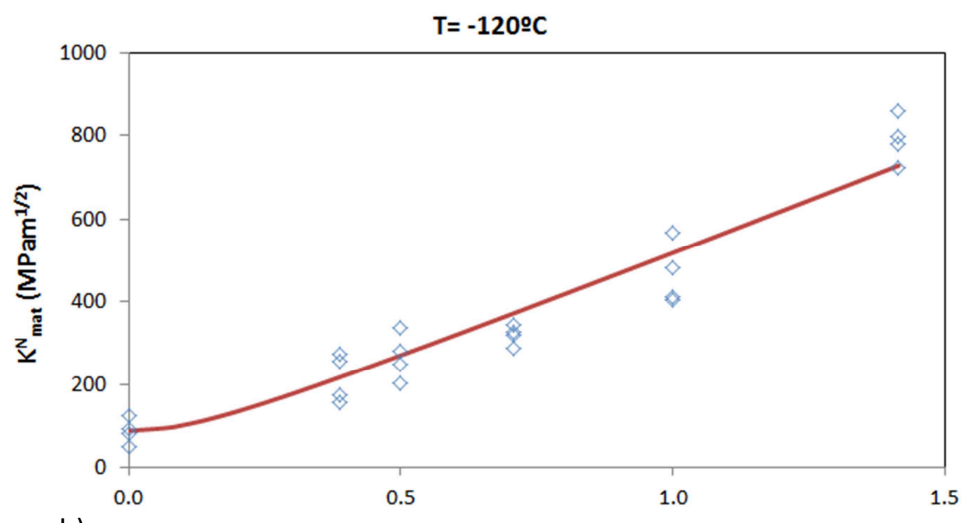

b)

$\rho^{1 / 2}$

— LM predictions $(\mathrm{L}=0.0075 \mathrm{~mm}) \quad \diamond$ experimental results

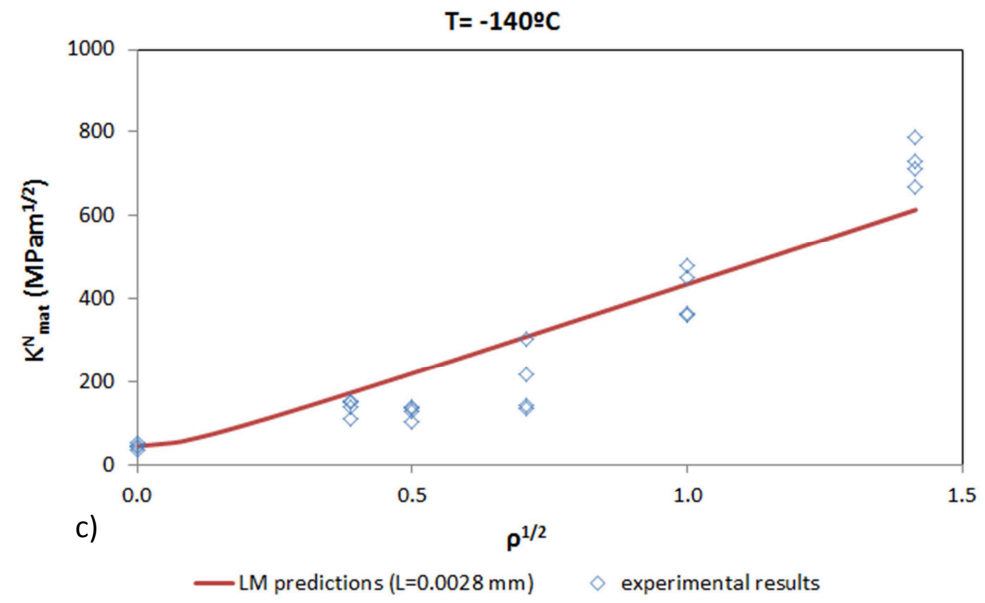

Figure 5. Apparent fracture toughness in steel S460M: experimental results and LM best fit predictions: a) $-100^{\circ} \mathrm{C}$; b) $-120^{\circ} \mathrm{C}$; c) $-140^{\circ} \mathrm{C}$. 


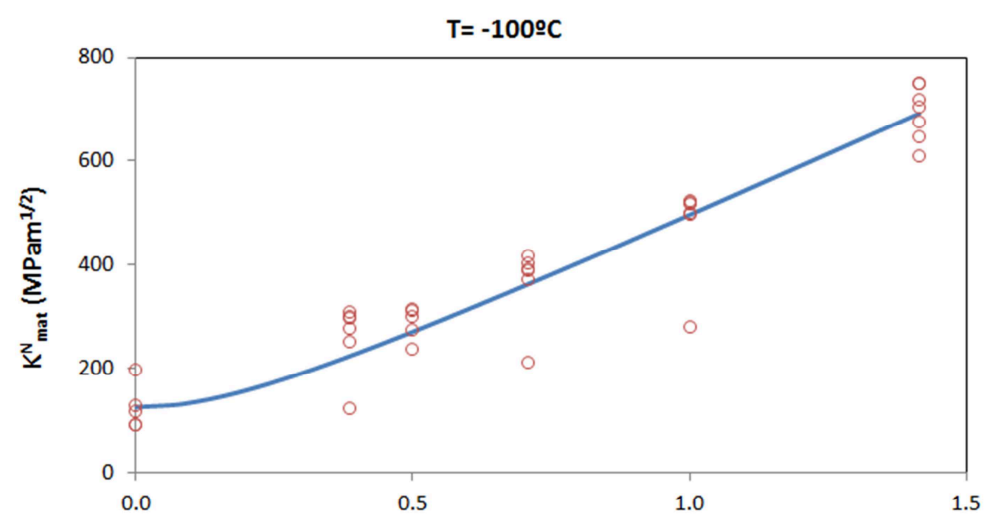

a)

$$
\rho^{1 / 2}
$$

—LM predictions $(\mathrm{L}=0.0170 \mathrm{~mm}) \quad \circ$ experimental results

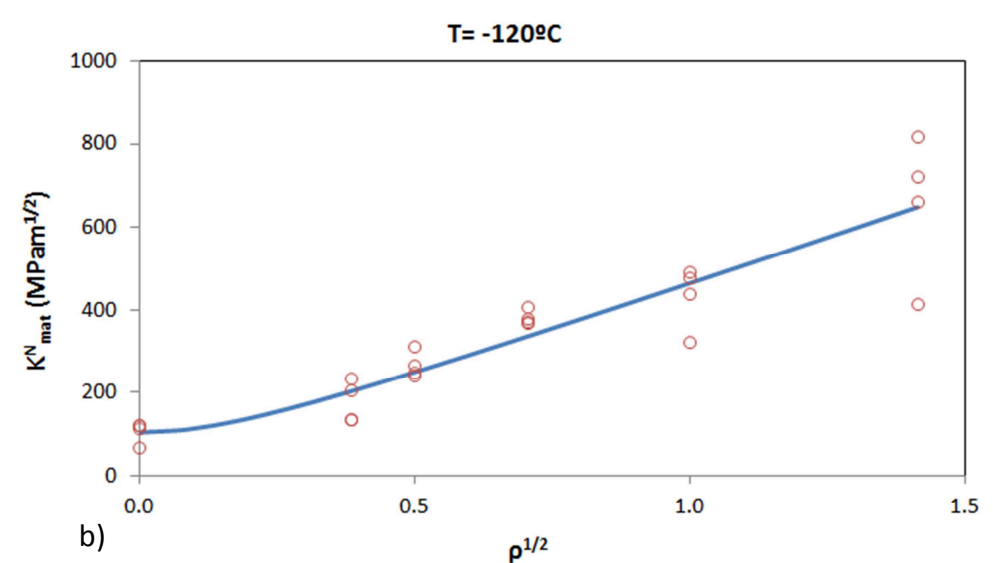

b)

$\rho^{1 / 2}$

— LM predictions $(\mathrm{L}=0.0131 \mathrm{~mm}) \quad \circ$ experimental results

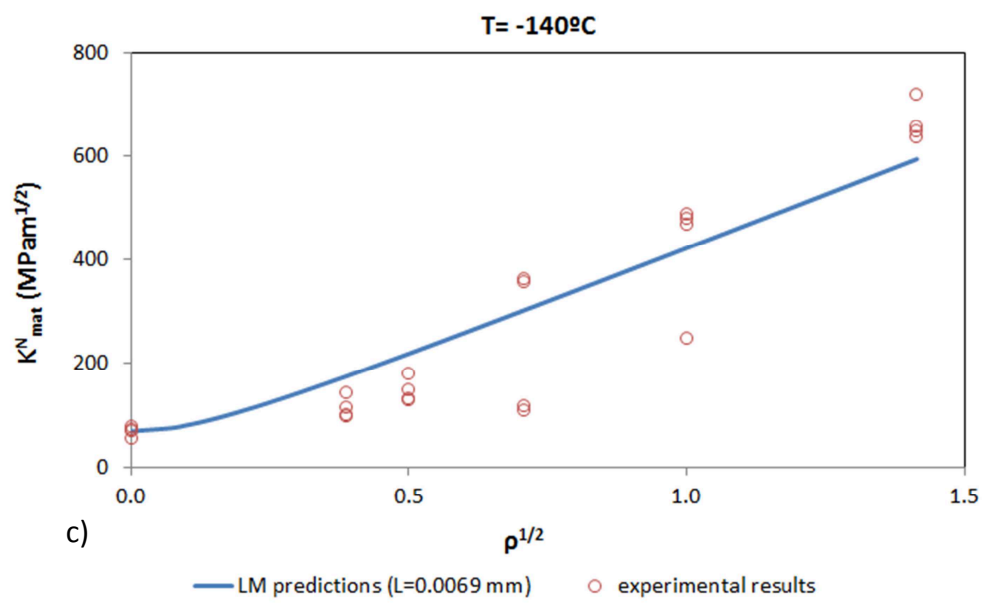

Figure 6. Apparent fracture toughness in steel S690Q: experimental results and LM best fit predictions: a) $-100^{\circ} \mathrm{C}$; b) $-120^{\circ} \mathrm{C}$; c) $-140^{\circ} \mathrm{C}$. 


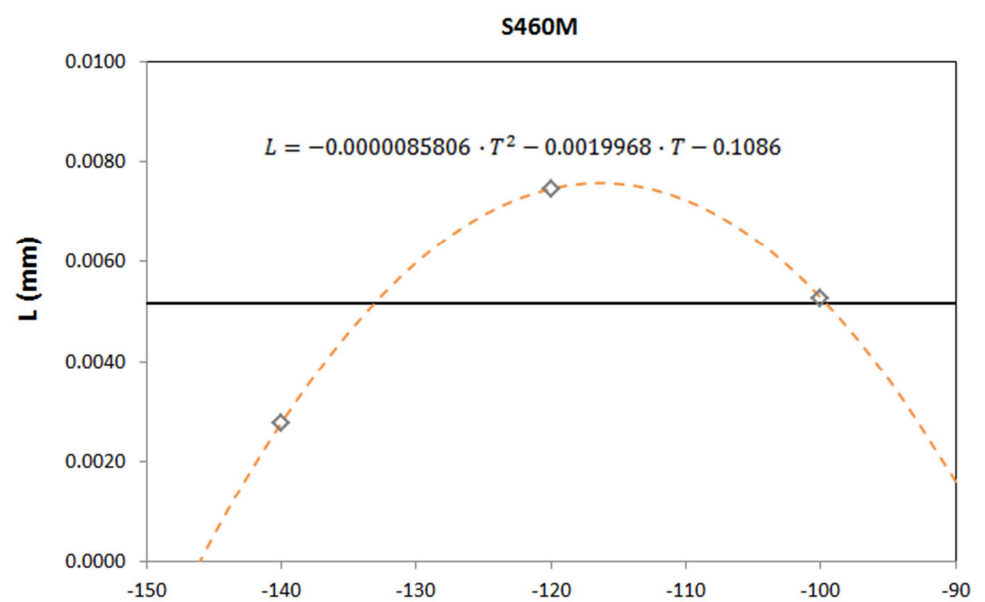

a)

$\mathrm{T}$ (으)

— L average value $(0.0052 \mathrm{~mm})$

$\diamond$ experimental data

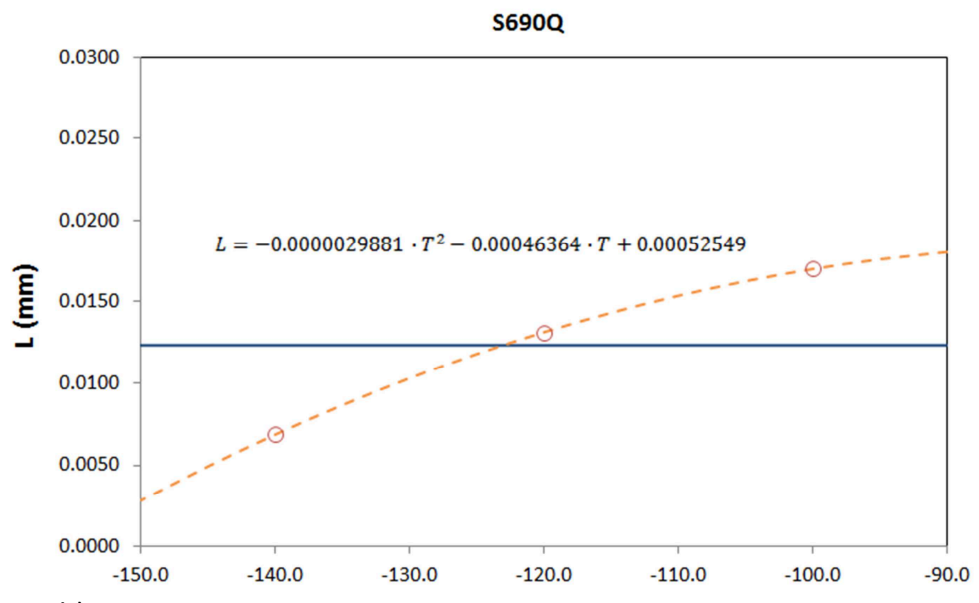

b)

$\mathrm{T}($ (ㅇ)

— L average value $(0.0115 \mathrm{~mm})$

$\bigcirc$ experimental data

Figure 7. $\mathrm{L}$ values at different temperatures, second order fitting equation and average value: a) steel S460M; b) steel S690Q. 


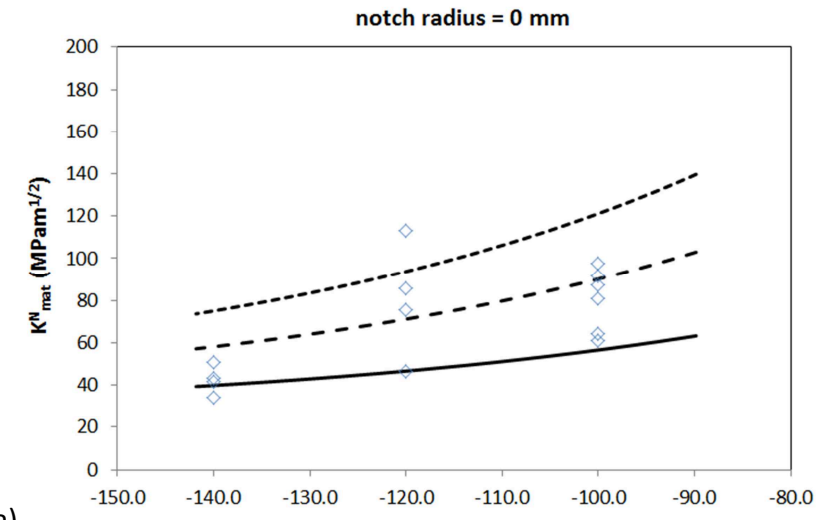

a)
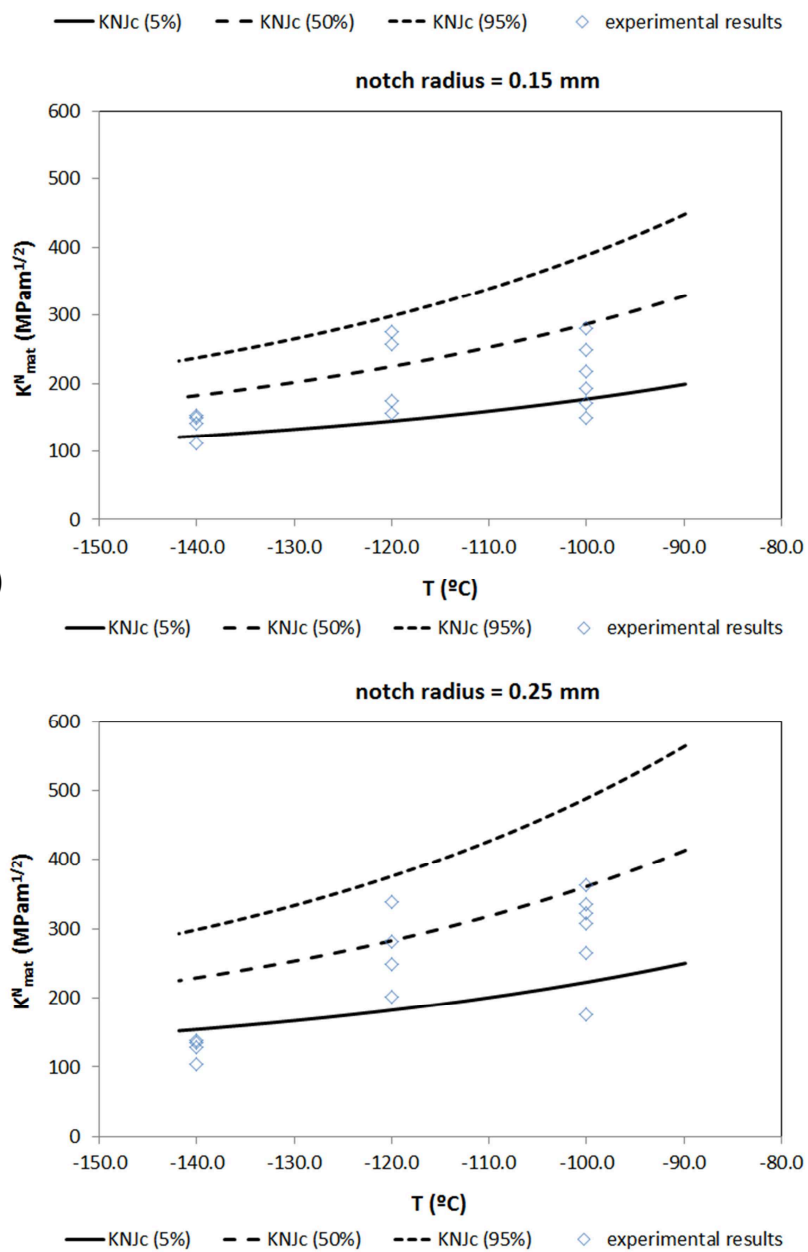

Figure 8. Comparison between experimental results and NMC predictions in steel S460M. $\mathrm{L}=0.0052 \mathrm{~mm}$ (average value): a) notch radius $=0 \mathrm{~mm}$ (crack-like defect); $\mathrm{b}$ ) notch radius $=$ $0.15 \mathrm{~mm}$; ) notch radius $=0.25 \mathrm{~mm}$. 

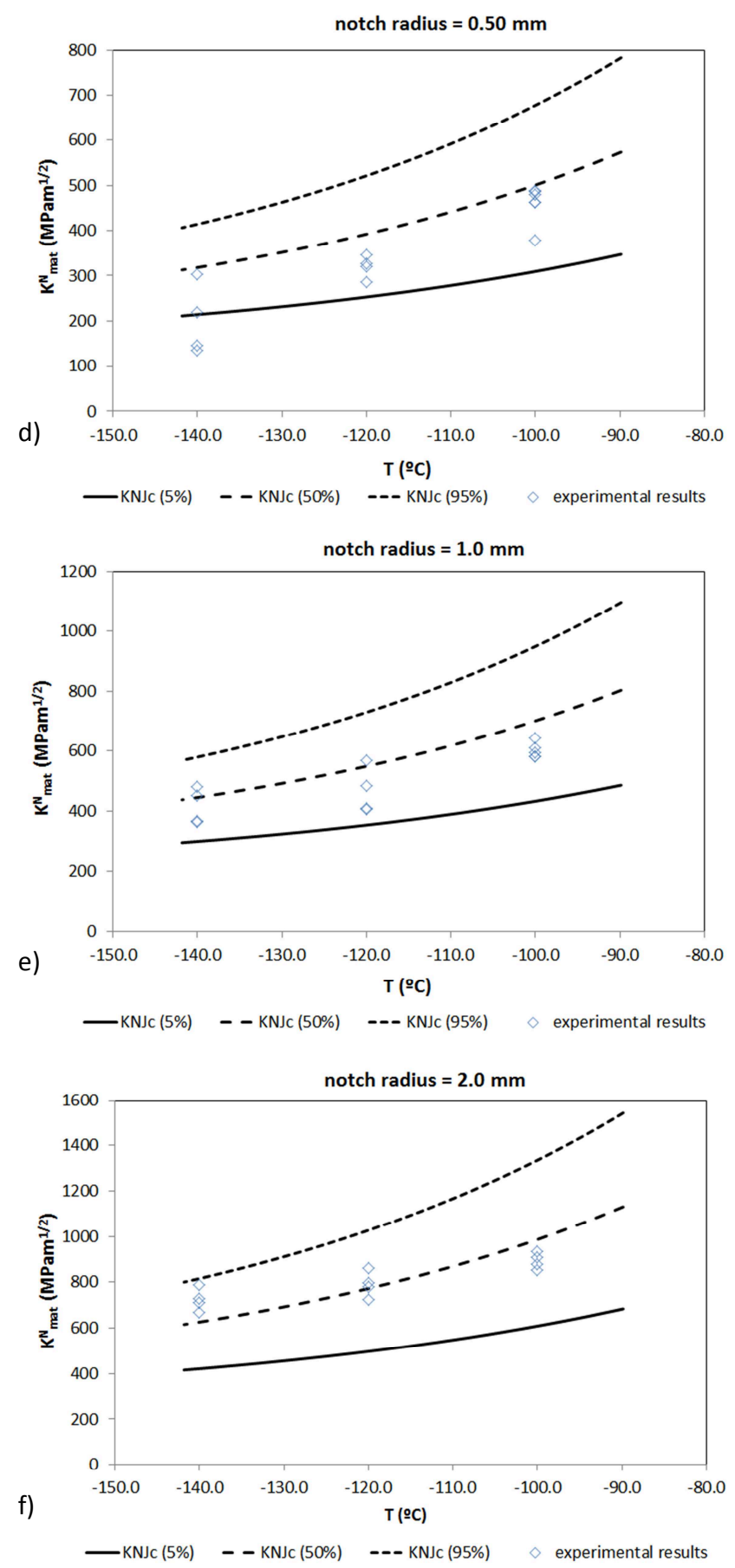

Figure 8 (cont.). Comparison between experimental results and NMC predictions in steel $\mathrm{S} 460 \mathrm{M}$. $\mathrm{L}=0.0052 \mathrm{~mm}$ (average value): $\mathrm{d}$ ) notch radius $=0.5 \mathrm{~mm}$; e) notch radius $=1.0 \mathrm{~mm}$; ) notch radius $=2.0 \mathrm{~mm}$. 

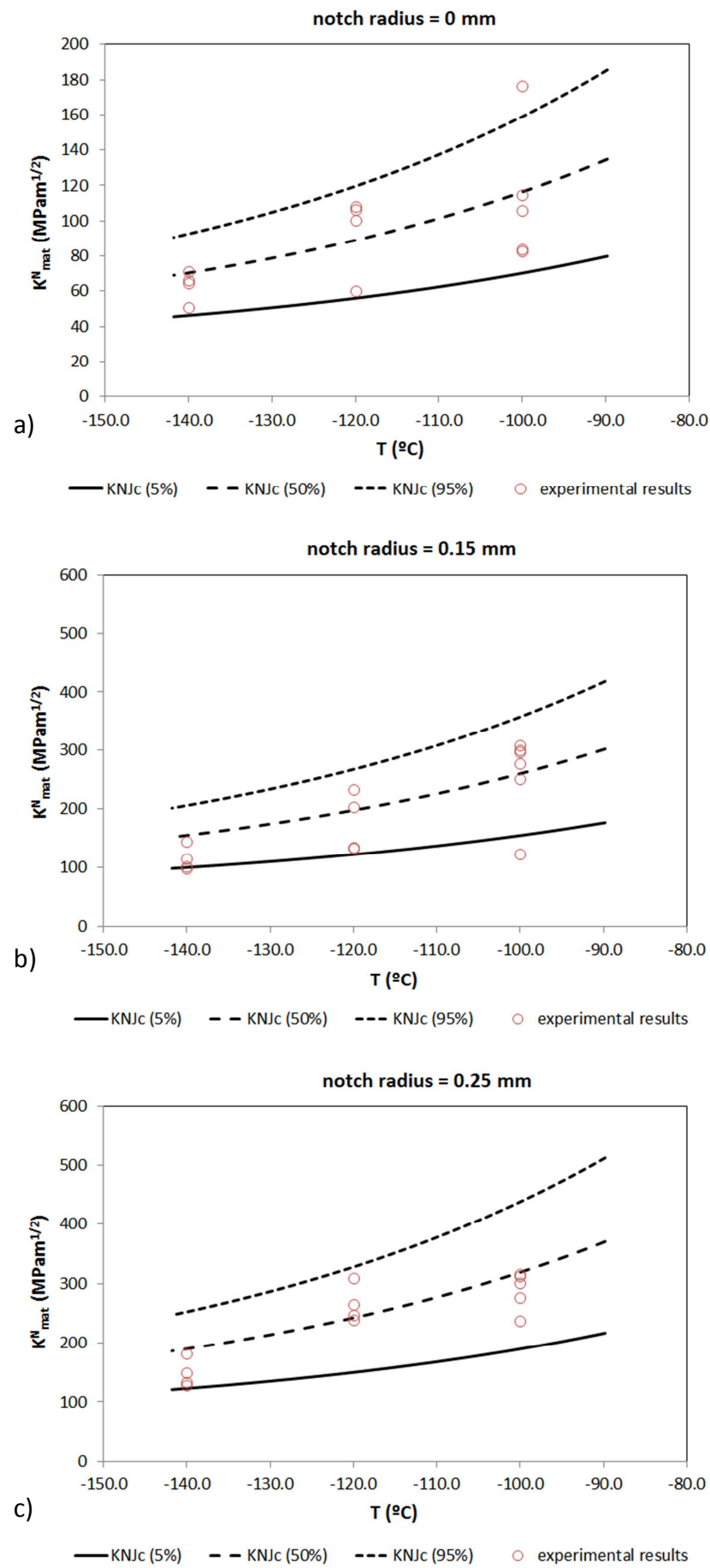

Figure 9. Comparison between experimental results and NMC predictions in steel S690Q. $\mathrm{L}=$ $0.0115 \mathrm{~mm}$ (average value): a) notch radius $=0 \mathrm{~mm}$ (crack-like defect); $\mathrm{b}$ ) notch radius $=0.15$ $\mathrm{mm} ; \mathrm{c}$ ) notch radius $=0.25 \mathrm{~mm}$. 

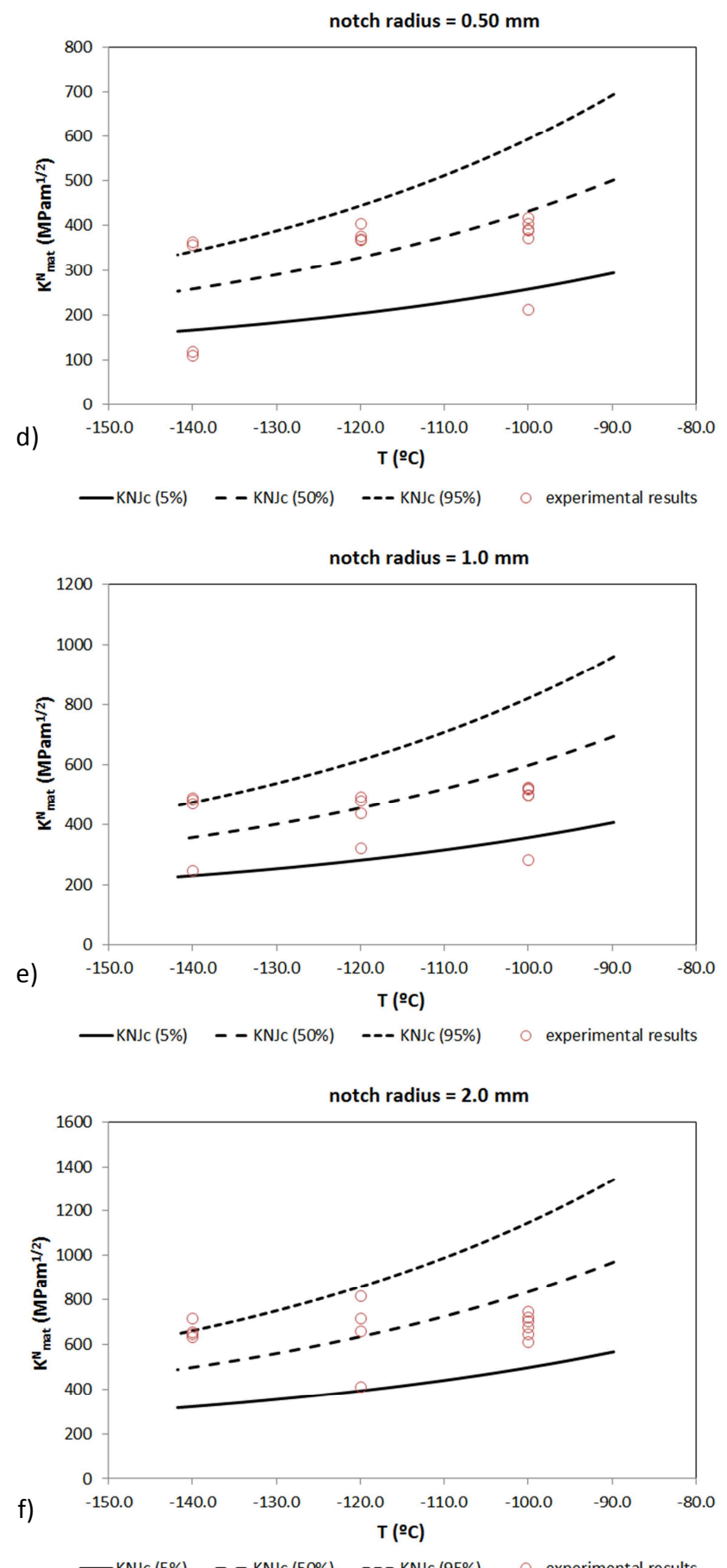

Figure 9 (cont.). Comparison between experimental results and NMC predictions in steel S690Q. $L=0.0115 \mathrm{~mm}$ (average value): $\mathrm{d}$ ) notch radius $=0.5 \mathrm{~mm} ; \mathrm{e}$ ) notch radius $=1.0 \mathrm{~mm} ; \mathrm{f}$ ) notch radius $=2.0 \mathrm{~mm}$. 


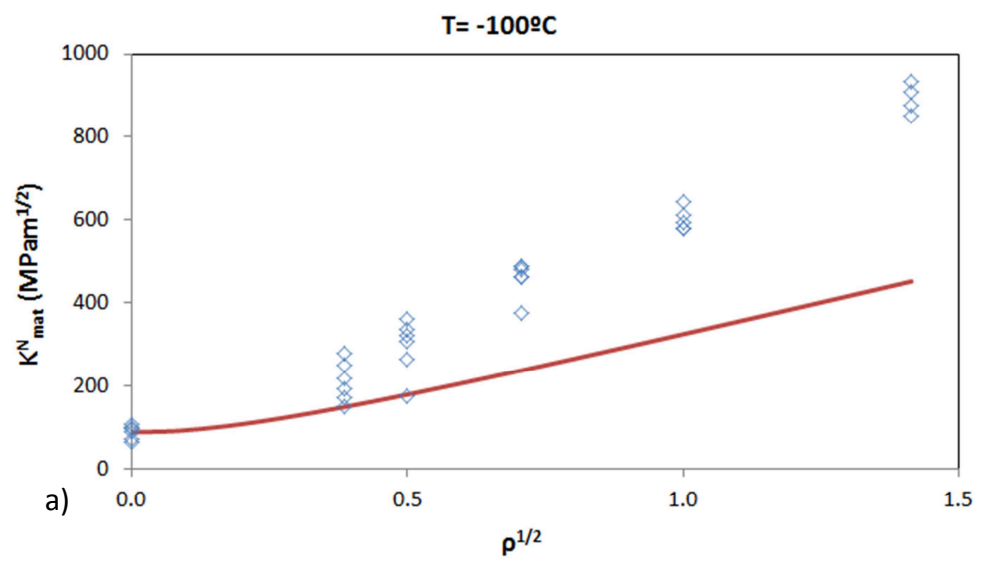

— $\mathrm{LM}$ predictions $(\mathrm{L}=0.02 \mathrm{~mm}) \quad \diamond$ experimental results

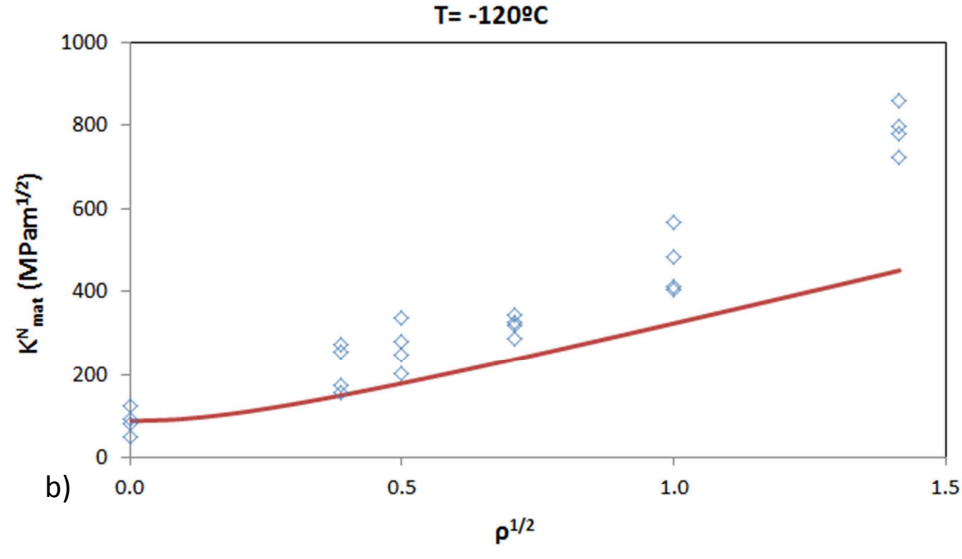

— LM predictions $(\mathrm{L}=0.02 \mathrm{~mm}) \quad \diamond$ experimental results

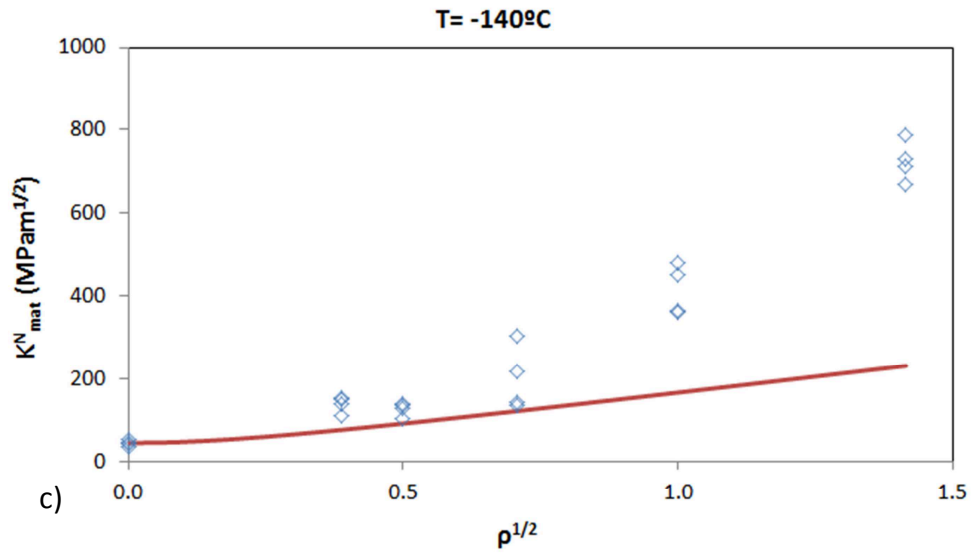

— LM predictions $(\mathrm{L}=0.02 \mathrm{~mm}) \quad \diamond$ experimental results

Figure 10. Apparent fracture toughness in steel S460M: experimental results and LM lower envelope: a) $-100^{\circ} \mathrm{C}$; b) $-120^{\circ} \mathrm{C}$; c) $-140^{\circ} \mathrm{C}$ 

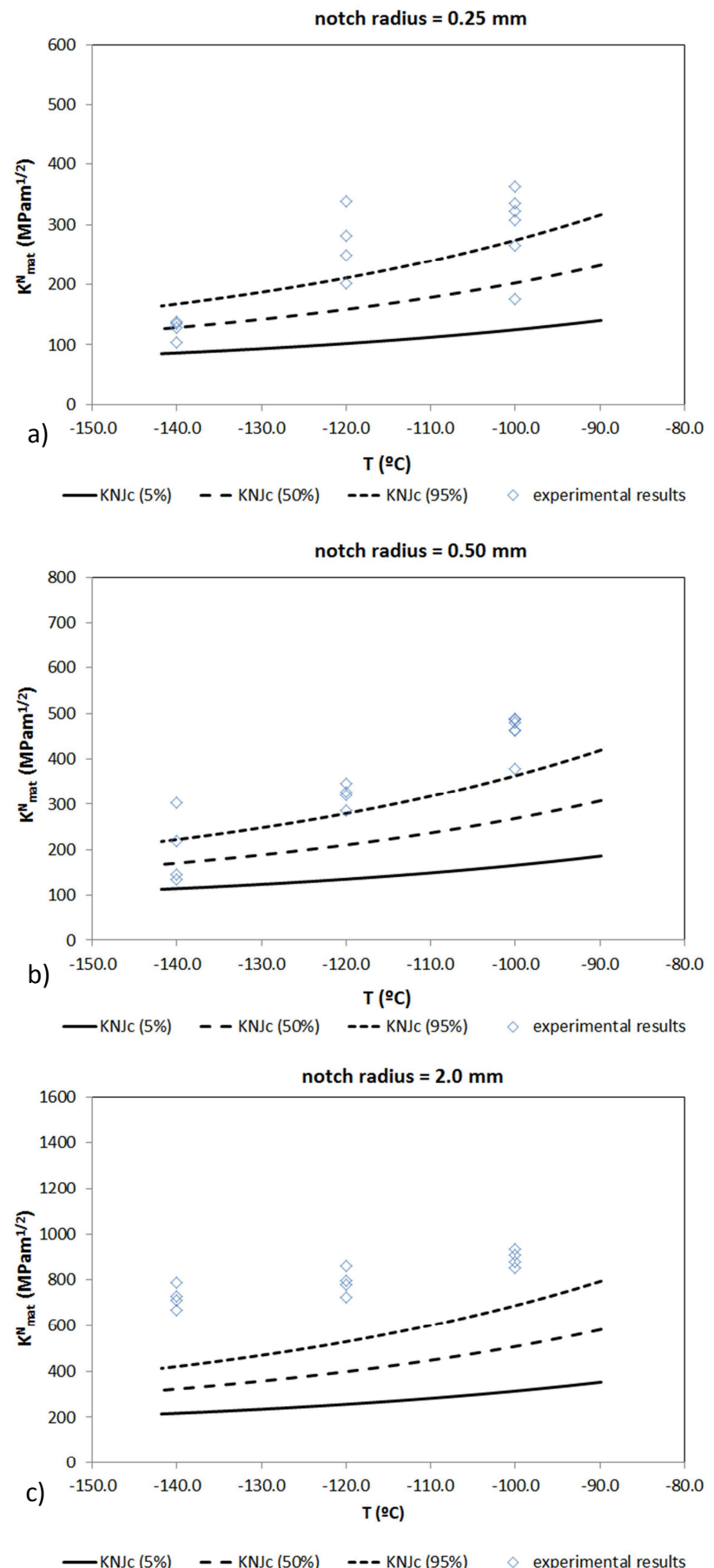

Figure 11. Comparison between experimental results and NMC predictions in steel S460M. $\mathrm{L}_{\mathrm{LE}}=0.02 \mathrm{~mm}$ (lower envelope): a) notch radius $=0.25 \mathrm{~mm}$; ) notch radius $=0.50 \mathrm{~mm} ; \mathrm{c}$ ) notch radius $=2.0 \mathrm{~mm}$. 